\title{
Tropical Cyclone Mekkhala's (2008) Formation over the South China Sea: Mesoscale, Synoptic-Scale, and Large-Scale Contributions
}

\author{
MYUNG-SOOK PARK \\ School of Urban and Environmental Engineering, Ulsan National Institute of Science and Technology, \\ Ulsan, South Korea \\ HYEONG-SEOG KIM \\ Ocean Science and Technology School, Korea Maritime and Ocean University, Busan, South Korea \\ CHANG-HOI Ho \\ School of Earth and Environmental Sciences, Seoul National University, Seoul, South Korea \\ RUSSELL L. ELSBERRY \\ Department of Meteorology, Naval Postgraduate School, Monterey, California \\ MYONG-IN LEE \\ School of Urban and Environmental Engineering, Ulsan National Institute of Science and \\ Technology, Ulsan, South Korea
}

(Manuscript received 5 April 2014, in final form 3 October 2014)

\begin{abstract}
Tropical cyclone formation close to the coastline of the Asian continent presents a significant threat to heavily populated coastal countries. A case study of Tropical Storm Mekkhala (2008) that developed off the coast of Vietnam is presented using the high-resolution analyses of the European Centre for MediumRange Weather Forecasts/Year of Tropical Convection and multiple satellite observations. The authors have analyzed contributions to the formation from large-scale intraseasonal variability, synoptic perturbations, and mesoscale convective systems (MCSs). Within a large-scale westerly wind burst (WWB) associated with the Madden-Julian oscillation (MJO), synoptic perturbations generated by two preceding tropical cyclones initiated the pre-Mekkhala low-level vortex over the Philippine Sea. Typhoon Hagupit produced a synoptic-scale wave train that contributed to the development of Jangmi, but likely suppressed the Mekkhala formation. The low-level vortex of the pre-Mekkhala disturbance was then initiated in a confluent zone between northeasterlies in advance of Typhoon Jangmi and the WWB. A key contribution to the development of Mekkhala was from diurnally varying MCSs that were invigorated in the WWB. The oceanic MCSs, which typically develop off the west coast of the Philippines in the morning and dissipate in the afternoon, were prolonged beyond the regular diurnal cycle. A combination with the MCSs developing downstream of the Philippines led to the critical structure change of the oceanic convective cluster, which implies the critical role of mesoscale processes. Therefore, the diurnally varying mesoscale convective processes over both the ocean and land are shown to have an essential role in the formation of Mekkhala in conjunction with large-scale MJO and the synoptic-scale TC influences.
\end{abstract}

Corresponding author address: Hyeong-Seog Kim, Ocean Science and Technology School, Korea Maritime and Ocean University, 727 Taejongro, Yeongdogu, Busan 606-791, South Korea. E-mail: hyeongseog@kmou.ac.kr

\section{Introduction}

Although tropical cyclone (TC) formation typically occurs because of atmospheric dynamic and thermodynamic processes over the open ocean, a number of TC 
formations occur rather close to land, which implies that some land surface processes may also have a contribution. The role of convection that originates over land or offshore has been recently emphasized for tropical cyclone formation over the eastern tropical Atlantic (e.g., Berry and Thorncroft 2005; Hopsch et al. 2010). In particular, diurnally evolving convection over the Guinea Highlands region of West Africa contributed to intensification of the precursor synoptic circulation to TC intensity (Ventrice et al. 2012). It is hypothesized in this study that similar mesoscale convections that originated over land contributed to TC formation over the western North Pacific as well.

In the western North Pacific, one of the main formation regions is the South China Sea (Kim et al. 2011) where development into a TC may lead to landfall on the Asian continent to the west and north within a period of 3 days. Such a TC formation poses a significant threat to heavily populated coastal regions. Predicting the timing and location of TC formation remains challenging (e.g., Nolan 2007; Fovell et al. 2009; Lang et al. 2012; Park et al. 2013). The extent to which physical processes over adjacent land areas may contribute to TC formation over the South China Sea is an additional complication. Although there have been several studies of TC processes over the South China Sea near the coastline regarding the convective structural change during landfall (e.g., Zhang et al. 2012) or air-sea interaction (e.g., Chen et al. 2014), TC formation near land has been not explored.

The primary objective of this study is to investigate contributions to a TC formation from the diurnally evolving mesoscale convective processes near and over the adjacent land. In particular, formation of the tropical depression that became Tropical Storm Mekkhala (2008) is studied as an example of TC formation near the Asian continent. The formation of the tropical depression occurred at 1800 UTC 27 September only about $300 \mathrm{~km}$ off the east coast of Vietnam, and it intensified into a tropical storm at 0000 UTC 29 September even closer to the Asian continent according to the Regional Specialized Meteorological Center (RSMC) Tokyo best track. A synoptic overview of the pre-Mekkhala and why this system should be further investigated will be given in section 2 .

Note that TC formation inherently involves multiscale processes. The large-scale variability modulates the favorable environmental conditions for TC formation (Harr and Elsberry 1995; references in section 4), and thus determines where a preexisting synoptic circulation can intensify (e.g., Li and Fu 2006; Li et al. 2006; references in section 5). A primary focus of the combined Tropical Cyclone Structure (TCS-08)/The Observing System Research and Predictability Experiment (THORPEX)
Pacific Asian Regional Campaign (T-PARC) was that mesoscale convective systems (MCSs) determine the location and timing of TC formation (Elsberry and Harr 2008). Therefore, this study will examine mesoscale contributions to the formation of the pre-Mekkhala depression in conjunction with large-scale intraseasonal variability and synoptic process. The datasets used for the analysis of these multiscale processes are described in section 3 and the contributions from large-scale intraseasonal variability, synoptic perturbation, and diurnally evolving MCSs are analyzed and discussed in sections 4,5 , and 6 , respectively. The summary and conclusions are given in section 7 .

\section{Synoptic overview of the pre-Mekkhala disturbance}

During the combined TCS-08/T-PARC field experiment, 51 TC precursor synoptic systems were monitored as to the possibility of a TC formation. The precursor low-level circulation of Mekkhala, which was the 46th system during the experiment (thus designated as TCS46), was first assumed to be associated with a tropical uppertropospheric trough (TUTT) that extended westward from the central Pacific (TCS-08/T-PARC field catalog daily report). High-level clouds in the Multifunctional Transport Satellite-1R (MTSAT-1R) infrared brightness temperatures on 15 September were initially identifiable in the southeastern quadrant of a deep, open trough ( $\mathrm{T}$ in Fig. 1a). However, the favorable influence of the TUTT on the low-level system was not sustained (Figs. 1b-d). By 18 September (Fig. 1b), a closed upper-level low (often called a cold-core low, L) broke off from the base of the TUTT. Convection within the TCS46 tended to be rather scattered in contrast to the highly organized pre-Hagupit depression (Bell and Montgomery 2010). While the convection was better organized over the Philippine Sea (Fig. 1c), the system remained as a nondeveloping system. Meanwhile, another disturbance to the east was developing into Typhoon Jangmi.

On 24 September (Fig. 1d), which was three days prior to the pre-Mekkhala depression formation, convective organization increased as the disturbance approached the Philippine Islands, and this will be considered as the initial phase of the formation. However, this development is not attributed to the upper-level cold low ( $\mathrm{L}$ in Fig. 1d) that was about $7^{\circ}-10^{\circ}$ latitude to the north of the pre-Mekkhala convective region.

At this time, Typhoon Hagupit was making landfall in the Guangdong Province of China to the northwest of the pre-Mekkhla disturbance (Fig. 1d). Carr and Elsberry (1995) showed that as a mature TC propagates due to the beta drift, Rossby wave dispersion (RWD) 


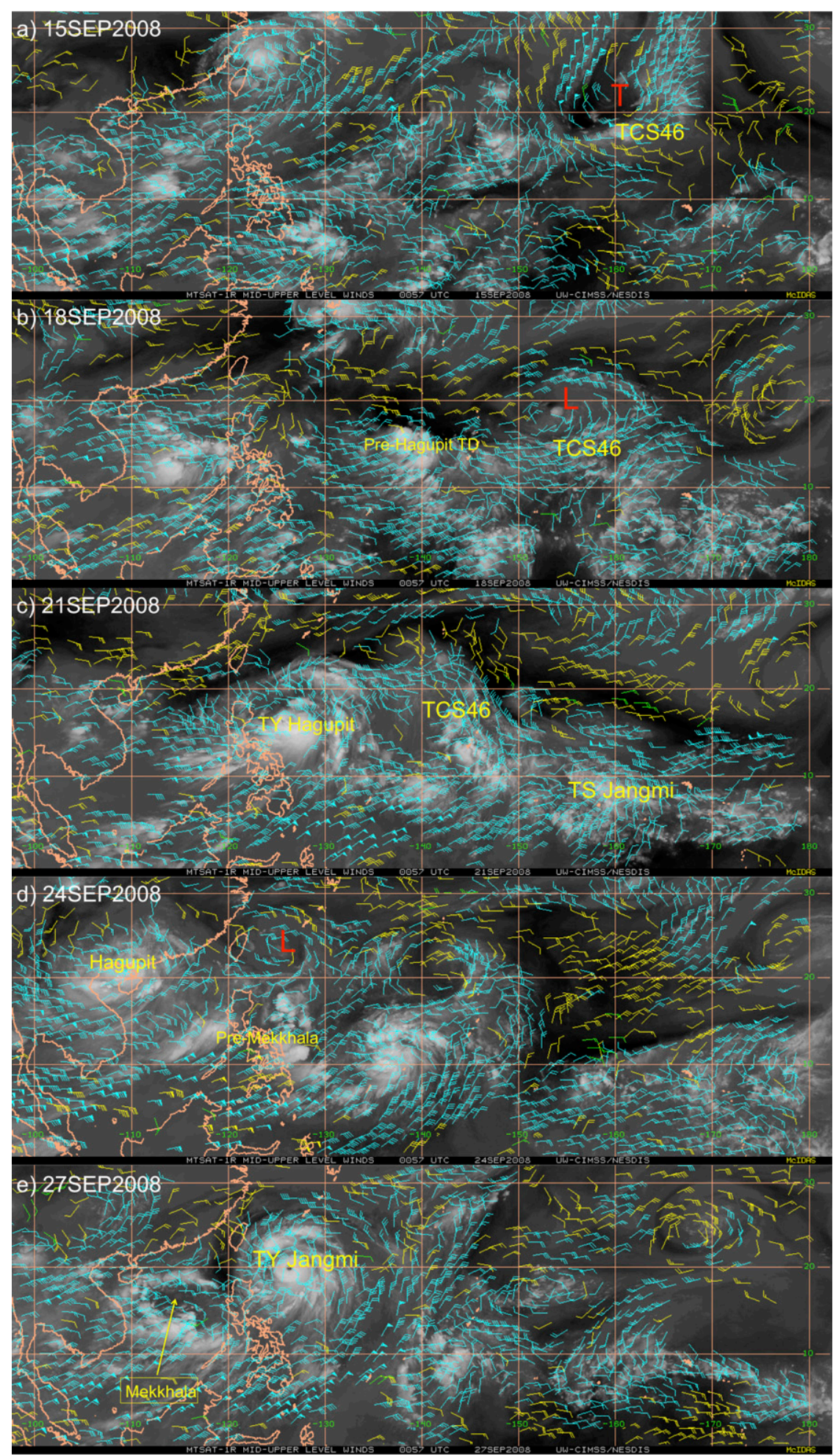

FIG. 1. (a)-(e) The MTSAT satellite-retrieved winds at midlevel (yellow barbs) and upper level (sky blue barbs) from the Cooperative Institute for Meteorological Satellite Studies (CIMSS) every 3 days from 15 Sep to 27 Sep 2008 for the pre-Mekkhala disturbance labeled TCS46. The tropical upper tropospheric trough (labeled "T") or the upper low (labeled "L") were at first assumed to be associated with the development of Mekkhala. 
may contribute to formation of a cyclonic circulation to the southeast ( $\mathrm{Li}$ et al. 2006). Thus, an alternate hypothesis was that the pre-Mekkhala disturbance was a result of RWD from Hagupit (section 5).

The multiple potential contributions to the formation of Mekkhala may make this a challenging case to give an accurate warning to the public. It was 25 September when the Joint Typhoon Warning Center (JTWC) began issuing assessments of the potential tropical cyclone formation for the disturbance over the South China Sea. However, the JTWC assessed its chances of becoming a "significant tropical cyclone" as "poor" (JTWC tropical weather advisory released at 0600 UTC 27 September 2008). Early on 28 September, the JTWC upgraded it to having a "good" chance and they soon issued a Tropical Cyclone Formation Alert (TCFA) within 24h (JTWC tropical weather advisory released at 0600 UTC 28 September 2008). Note that the RSMC best track lists the tropical depression declaration time as 1800 UTC 27 September.

Such a delayed warning may be partly attributed to a lack of accurate formation guidance from operational numerical weather prediction systems. For example, global forecast systems such as the Navy Operational Global Atmospheric Prediction System (NOGAPS) and the Met Office did not predict the closed cyclonic circulation on 27 September until $48 \mathrm{~h}$ before the formation time (not shown). Delayed warnings are important because Mekkhala had intensified to a 50-kt $(1 \mathrm{kt}=$ $0.5144 \mathrm{~m} \mathrm{~s}^{-1}$ ) tropical storm by 30 September and made landfall over Vietnam with at least 16 deaths and an estimated $\$ 6.6$ million (U.S. dollars) in property damage. ${ }^{1}$

\section{Datasets}

High-resolution analyses from the European Centre for Medium-Range Weather Forecasts (ECMWF) prepared for the Year of Tropical Convection (YOTC) were available for the examination of the large-scale and synoptic-scale circulation evolution. Since the World Climate Research Programme (WCRP) and WWRP/ THORPEX coordinated the YOTC observing, modeling, and forecasting of organized tropical convection, a more realistic representation in the global analyses is expected (Waliser et al. 2012). The horizontal resolution of the ECMWF analyses is $0.25^{\circ}$, and analyses were available each $6 \mathrm{~h}$.

\footnotetext{
${ }^{1}$ Associated Press, cited 2009: Vietnam gets pounded by another deadly storm. MSNBC, 10 October 2008. [Available online at http:// www.nbcnews.com/id/26990852/ns/weather/t/vietnam-gets-poundedanother-deadly-storm/\#.VFp78fnF9qV.]
}

Rainfall amounts are from the Tropical Rainfall Measuring Mission (TRMM) Multisatellite Precipitation Analyses (TMPA), which are available every $3 \mathrm{~h}$ with a $0.25^{\circ}$ latitude $\times 0.25^{\circ}$ longitude resolution between $50^{\circ} \mathrm{S}$ and $50^{\circ} \mathrm{N}$. This global rainfall product is derived by merging geostationary infrared [e.g., Geostationary $\mathrm{Op}$ erational Environmental Satellite-9 (GOES-9)] and polarorbiting passive microwave (e.g., TRMM) observations, and rain gauge measurements (Huffman et al. 2007). The reliability of TMPA for the diurnal variations has been established by comparisons with rain gauge data (Sapiano and Arkin 2009). Diurnal variations of the convection are analyzed from the MTSAT-1R infrared (IR) color images provided by the Naval Research Laboratory. These images are also available in the TPARC/TCS-08 Field Catalog (http://catalog.eol.ucar.edu/).

Other TRMM datasets were used to examine the convective structure just prior to the TC formation: radar reflectivity in the Precipitation Radar (PR) 2A25 and microwave brightness temperature in the TRMM Microwave Imager (TMI) 1B11 data. The 2A25 dataset includes three-dimensional reflectivity at $13.8 \mathrm{GHz}$ from near the surface to $20-\mathrm{km}$ height within a $215-\mathrm{km}$ swath. Horizontal and vertical resolutions of the PR data are $5 \mathrm{~km}$ and $250 \mathrm{~m}$, respectively (Iguchi et al. 2000). The distribution of the PR reflectivities is investigated as a proxy of overshooting convective towers (i.e., hot towers) as in Jiang et al. (2013). The TMI 2A12 algorithm uses observations within a $760-\mathrm{km}$-wide swath from all the TMI frequencies $(10.7,19.3,21.3,37.0$, and $85.5 \mathrm{GHz}$, which are dual polarized except for $21.3 \mathrm{GHz}$ ). Among the channels, polarized corrected temperature (PCT) at $85 \mathrm{GHz}$ is used in this study since it responds to ice scattering in the deep convective towers. The TMI TBs at $85.5 \mathrm{GHz}$ have effective fields of view of $7 \mathrm{~km} \times 5 \mathrm{~km}$ (Park et al. 2007).

An MCS analysis tool from the University of Utah Precipitation Measuring Missions Science (Liu et al. 2008; $\mathrm{http} / /$ trmm.chpc.utah.edu/) is applied for visualizing the structure of the MCS leading to TC formation. The tool defines an MCS as a system with contiguous precipitating area greater than $2000 \mathrm{~km}^{2}$ from TRMM observations, and enables visualization of the three-dimensional PR reflectivities, the TMI PCTs, and the Visible and Infrared Radiometer (VIS) infrared brightness temperatures.

\section{Contribution from large-scale intraseasonal variability}

It is well known that the large-scale environment associated with the MJO and equatorial Rossby wave modulates TC formation (Harr and Elsberry 1995; Maloney and Hartmann 2001; Bessafi and Wheeler 2006; 
(a) IRMM1, RMM2) phase space for 22-Rug-2008 to 30-5ep-2008

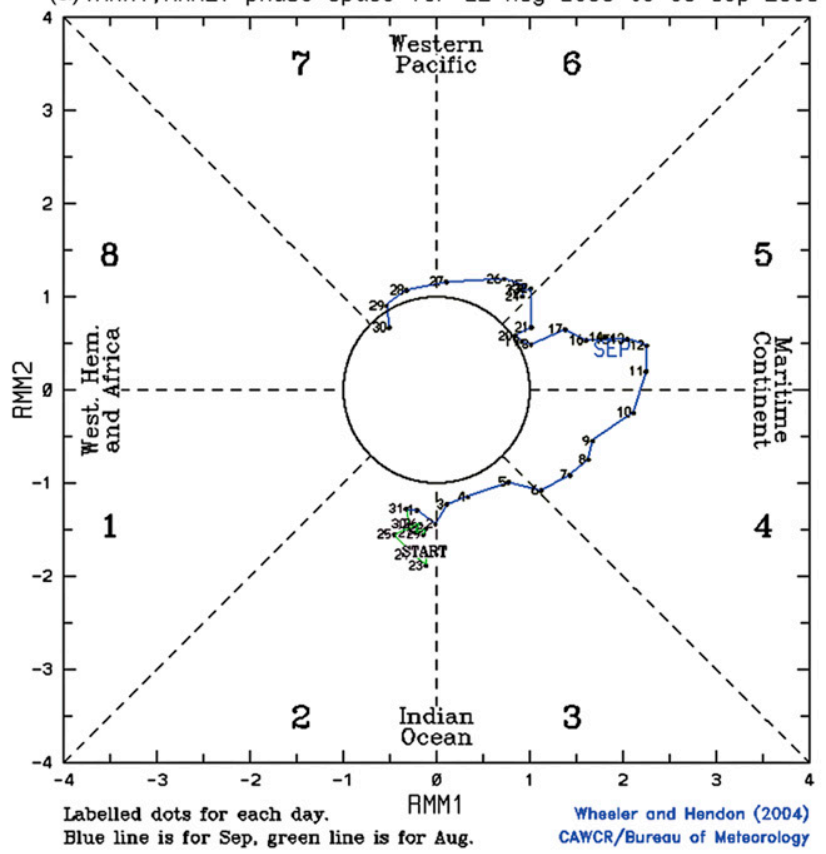

(b) 15 SEP2008

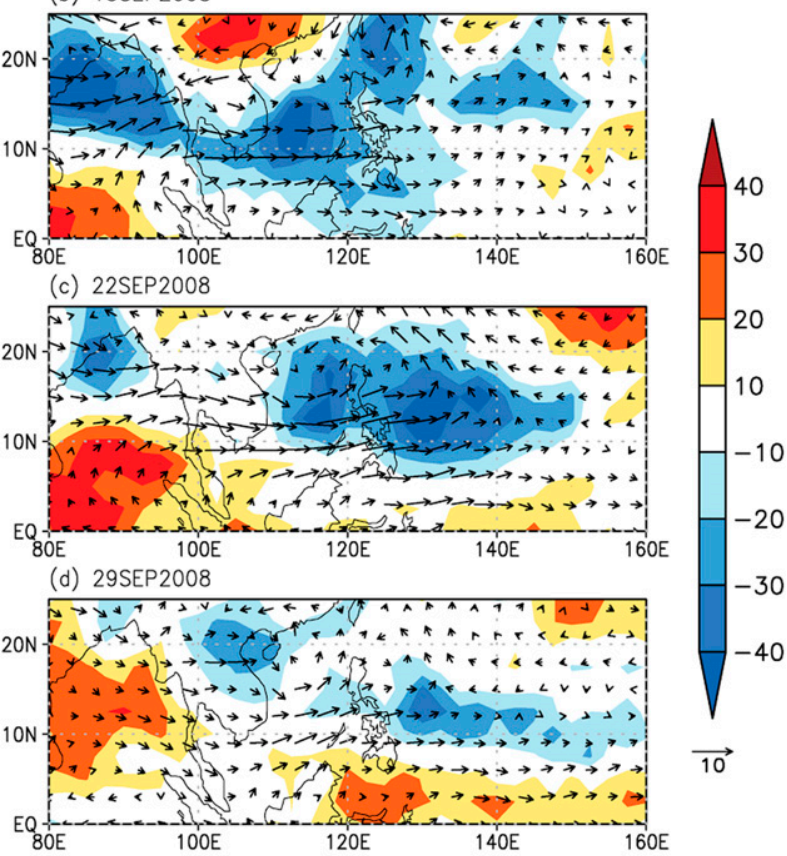

FIG. 2. (a) Phase diagram of RMM1 and RMM2 from the Centre for Australian Weather and Climate Research/Bureau of Meteorology for August (green line) and for September (blue line) during 2008. Dots and numbers indicate the days of the month. The MJO-related circulations in the vicinity of the South China Sea are illustrated using the 20-100-day bandpass-filtered OLR (shading) and 850-hPa winds (vectors) on (b) 15 Sep, (c) 22 Sep, and (d) 29 Sep 2008.

Molinari et al. 2007; Kim et al. 2008). Harr and Elsberry (1995) show that active (inactive) periods of TCs occur when the large-scale circulation anomalies represent an active (inactive) monsoon trough. Maloney and Hartmann (2001) showed that the barotropic energy conversion from the mean flow is larger during an active MJO period in the western North Pacific, which may also contribute to more frequent TC formations. Molinari et al. (2007) documented that the climatological background over the western North Pacific (e.g., lower-tropospheric convergence and easterly shear) is favorable for amplification and scale contraction of equatorial Rossby (ER) waves, which highlights the role of ER waves as precursor disturbances for tropical cyclones.

During the time when the pre-Mekkhala depression develops, the MJO was dominant (Fig. 2) but the ER wave was inactive (not shown) in the western Pacific. A well-defined MJO was observed throughout September 2008. Based on the Real-time Multivariate MJO series 1 (RMM1) and RMM2 (Wheeler and Hendon, 2004; Straub 2013) as in Fig. 2a, the MJO phase changed from 2 to 5 during 1-21 September 2008. The MJO was active throughout September as indicated by the large amplitude (generally 1.0-2.5) and counterclockwise propagation. On 22 September it transitioned to phase 6, which is generally associated with enhanced convection in the western Pacific. While the RMM is a valuable tool for tracking the $\mathrm{MJO}$, it can be sensitive to higherfrequency equatorial wave (Roundy et al. 2009). Thus, the 20-100-day bandpass-filtered OLR and 850-hPa winds were examined. Figures $2 b-d$ reconfirmed that the MJO-related cloud clusters had propagated eastward from the Indian Ocean to the Maritime Continent. In particular, when the MJO-related cloud clusters were located in the western Pacific (phases 6-7), strong largescale westerlies prevailed over the South China Sea (Figs. 2c,d). These large-scale westerlies induce abundant air-sea fluxes to produce a warm, moist airstream that is favorable for vigorous convection. While lowlevel warm and moist air is a necessary but not sufficient condition for TC formation, a natural question is how to differentiate the MJO-influenced likely formation days from the nonformation days.

Another likely contribution of the westerly wind burst (WWB) associated with MJO phase 6 is enhanced crossequatorial flow in the region of $105^{\circ} \mathrm{E}$ that facilitates development of the pre-Mekkhala monsoon depression in the South China Sea (Beattie and Elsberry 2012). In the next two sections it will be demonstrated that the Mekkhala formation also involved contributions from two TC circulations and from mesoscale processes within this favorable large-scale circulation related to MJO phase 6. 


\section{Contribution from synoptic perturbation associated with Hagupit}

It was hypothesized in section 2 that the preceding Typhoon Hagupit may have had an influence on the preMekkhala formation over the Philippines (Fig. 1d). In section 5a, the evolution of the cyclonic low-level circulation that will later result in the Mekkhala formation will be described. How this low-level circulation affected the formation will be investigated in section $5 b$.

\section{a. Evolution of low-level circulation related to Mekkhala formation}

The evolution of the low-level circulations and the TRMM 3B42 precipitation related to the formation of Mekkhala during 23-26 September are shown in Figs. 3 and 4. On 23 September, the pre-Makkhala disturbance was only an open trough near $16^{\circ} \mathrm{N}, 130^{\circ} \mathrm{E}$ (dashed box; Figs. $3 \mathrm{a}$ and $3 \mathrm{c}$ ) with an associated band of convection with embedded areas of heavy precipitation (Fig. 4a). Although small positive potential vorticity (PV) maxima (Figs. 3a,b) are analyzed within the convection region over the Philippine Sea, organization of these smallerscale vortices was likely being inhibited by strong vertical wind shear due to superposition of the anticyclonic outflow of Typhoon Hagupit (not shown). Farther to the southeast along the monsoon trough, the pre-Jangmi disturbance was developing rapidly throughout 23 September, and JTWC upgraded it to a tropical depression at 1200 UTC 23 September and to Tropical Storm Jangmi at 0000 UTC 24 September.

At 0000 UTC 24 September (Fig. 3c), the pre-Mekkhala disturbance was somewhat enhanced at low levels, which is noteworthy as this cyclonic vorticity spinup was occurring $15^{\circ}$ longitude to the southeast of the center of the large Typhoon Hagupit as it was making landfall. Carr and Elsberry (1995) documented other cases of RWD when landfall caused rapid decay of a typhoon. Strong convective cells with heavy precipitation (rain rate $\geq 8 \mathrm{~mm} \mathrm{~h}^{-1}$ ) based on the TRMM 3B42 (Figs. 4c,d) were observed east of the Philippines that were almost collocated with PV vortices in the ECMWF low-level analyses (Figs. 3c,d). Thus, the low-level vortex evolution is considered to have resulted from convergence/stretching due to latent heating in deep convective cells. By 1200 UTC 24 September (Fig. 3d), the PV vorticities are elongated, which may imply vortex filamentation and merging as in laboratory experiments or numerical simulations (Griffiths and Hopfinger 1987).

By 0000 UTC 25 September (Fig. 3e), a region of positive PV anomalies with a horizontal scale of about $300-\mathrm{km}$ diameter became organized over the east coast of the Philippines, which hereafter is indicated as "vortex core $\alpha . "$ At the same time, large-scale southwesterlies extended across the South China Sea to the vortex core. Whereas these southwesterlies had previously been incorporated into the outer region of Typhoon Hagupit, they are considered to be a reflection of the well-defined MJO during September 2008 as described in section 4. Two mesoscale cyclonic circulations (two dashed circles in Fig. 3f) formed by 1200 UTC 25 September possibly in association with convective processes (Fig. 4f) on the cyclonic shear side of the large-scale southwesterlies. These MCSs in the central South China Sea and just off the west coast of the Philippines and their contribution to the formation of Mekkhala will be investigated in section 6 .

By 0000 UTC 26 September, a broad, closed cyclonic circulation with a diameter of about $1000 \mathrm{~km} \mathrm{(M} \mathrm{in}$ Fig. 3g) had formed over the South China Sea. While two PV maxima that were likely the residuals of the two MCSs at 1200 UTC 25 September were present within the circulation, the strongest winds existed along the perimeter of the circulation. Thus, this circulation had the characteristics of a monsoon depression (Harr and Elsberry 1996; Beattie and Elsberry 2012) rather than a TC since the central core of convection and cyclonic circulation of a TC were not yet present (Fig. 3g). By 1200 UTC 26 September (Fig. 3h), the two PV maxima had consolidated near the center of circulation. However, the deep convection and precipitation were not near the center; rather, a band of precipitation extended around the west side and farther to the south off the coast of the southern Philippine islands (Fig. 4h). Consequently, Mekkhala was classified as a tropical depression and later a tropical storm rather than a typhoon.

In summary, it is hypothesized that the development of vortex core $\alpha$ over the Philippine Sea during the period of 24-25 September was an essential element for the Mekkhala formation. This initial vortex core then interacted with the two other vorticies (dashed circles in Fig. 3f) over the South China Sea to form a monsoon depression that later transformed into the preMekkhala tropical depression on 27 September. While these mesoscale contributions over the South China Sea will be investigated in section 6 , the synoptic-scale processes considered to be responsible for the initial vortex will be described in section $5 b$.

\section{b. Influence of the preceding TC on the initial low-level cyclonic vortex evolution}

Since the development of the initial vortex core $\alpha$ over the Philippine Sea occurred southeast of Typhoon Hagupit, an RWD pathway from Hagupit to this vortex was hypothesized. The positive impact of the RWD on TC formation has been investigated in many previous studies (e.g., Carr and Elsberry 1995; Li and Fu 2006; 

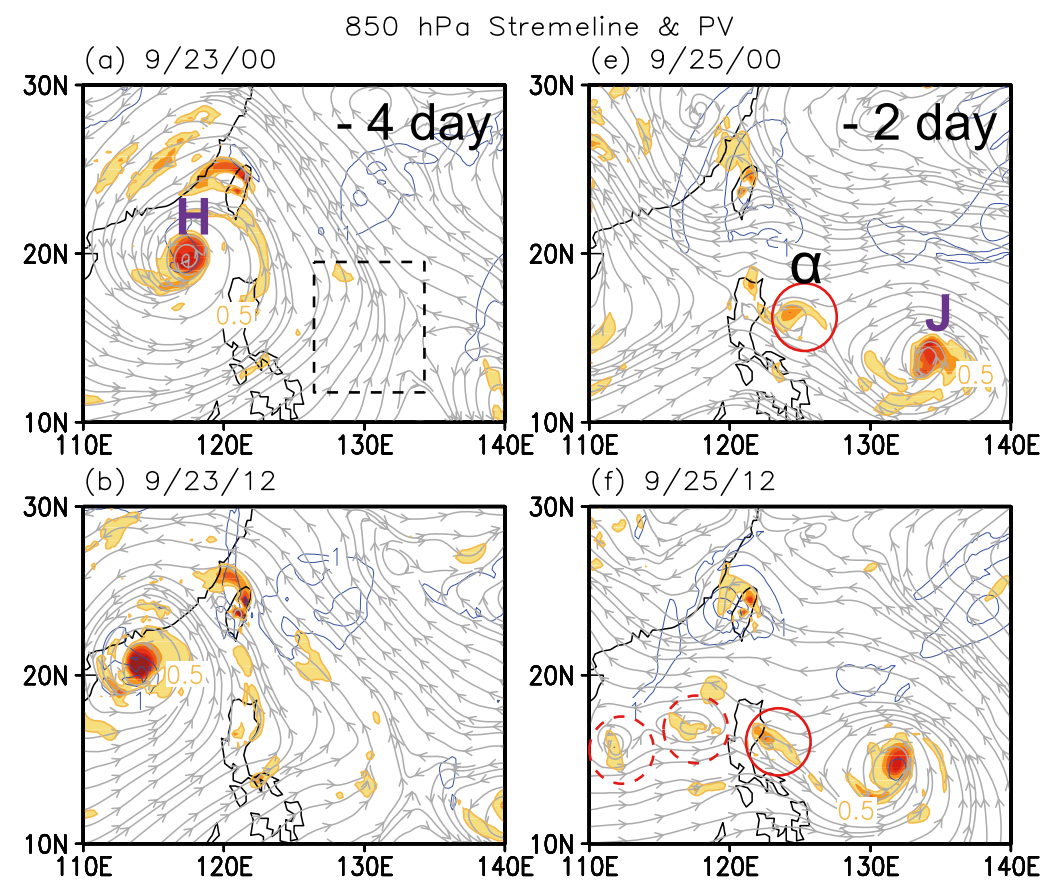

(f) $9 / 25 / 12$
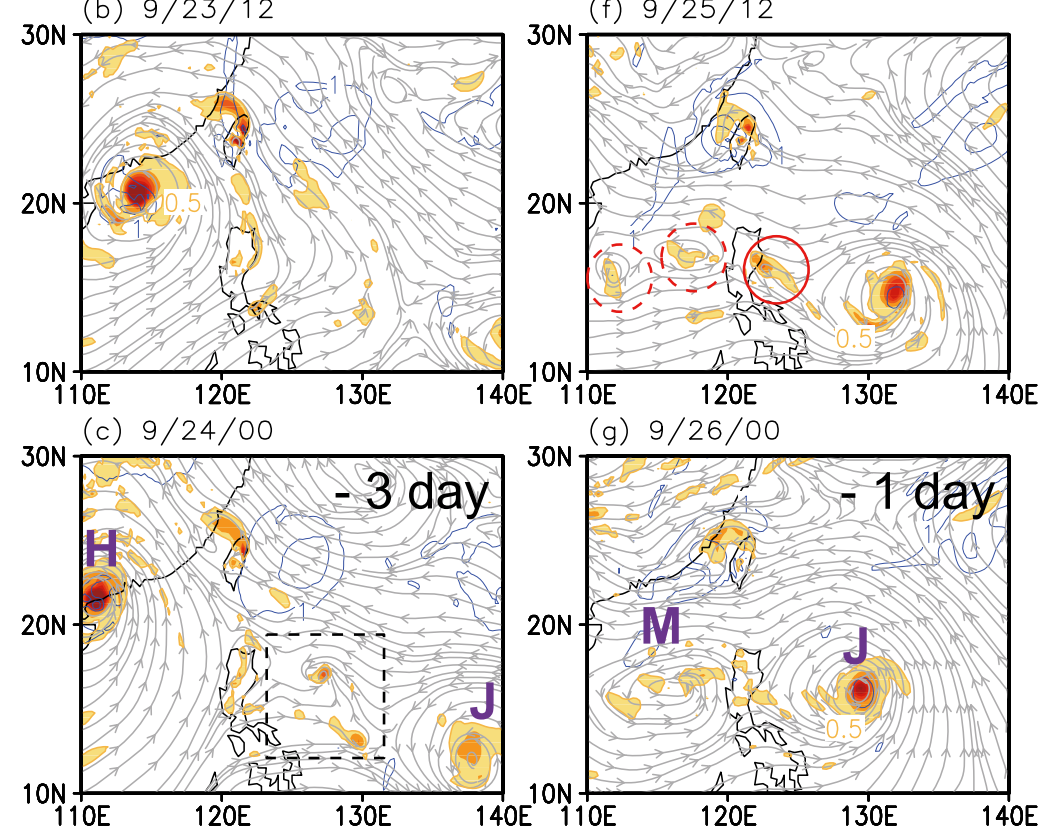

(d) $9 / 24 / 12$

(h) $9 / 26 / 12$

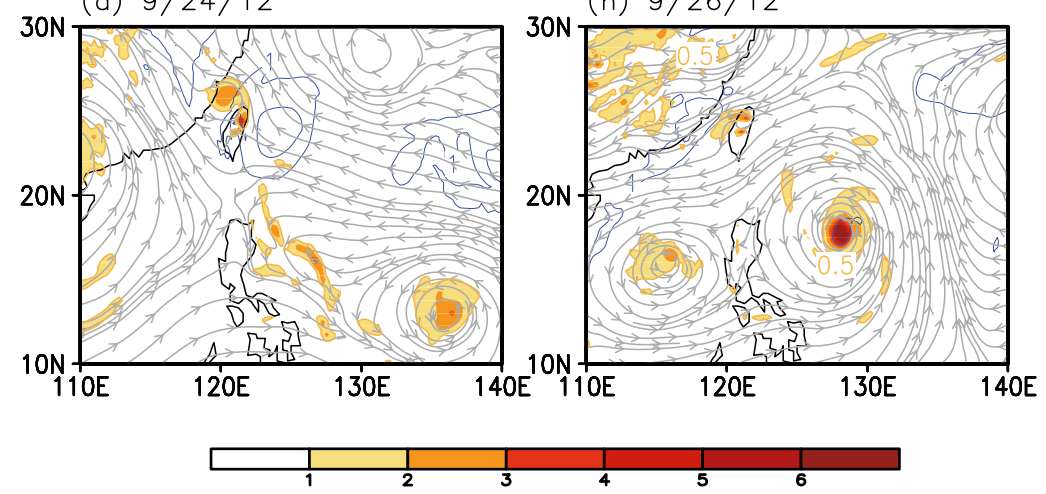

FIG. 3. (a)-(h) Analyses from ECMWF/YOTC dataset each $12 \mathrm{~h}$ from 0000 UTC 23 Sep to 1200 UTC 26 Sep of 850-hPa streamlines and PV (shadings, color bar at bottom) and 200-hPa PV (blue contour). The unit of PV is potential vorticity unit (PVU, 1 PVU = $10^{-6} \mathrm{~K} \mathrm{~kg}^{-1} \mathrm{~m}^{2} \mathrm{~s}^{-1}$ ). The area where the initial pre-Mekkhala vortex was developing [black dashed box in (a)] moved westward from the Philippine Sea toward the South China Sea in (c). The initial core vortex of the pre-Mekkhala disturbance that was organized over the Philippine Sea is indicated by a red circle as " $\alpha$ " in (e) and (f). Two other cyclonic vortex cores that later contributed to formation of pre-Mekkhala depression are marked by red dashed circles in (f). For the 0000 UTC analyses, all tropical cyclones and the precursors having any synoptic-scale, closed low-level cyclonic circulation are marked as " $\mathrm{H}$ " and " $\mathrm{J}$ " for Hagupit and Jangmi, and as " $\mathrm{M}$ " for the preMekkhala, respectively. 
Precipitation
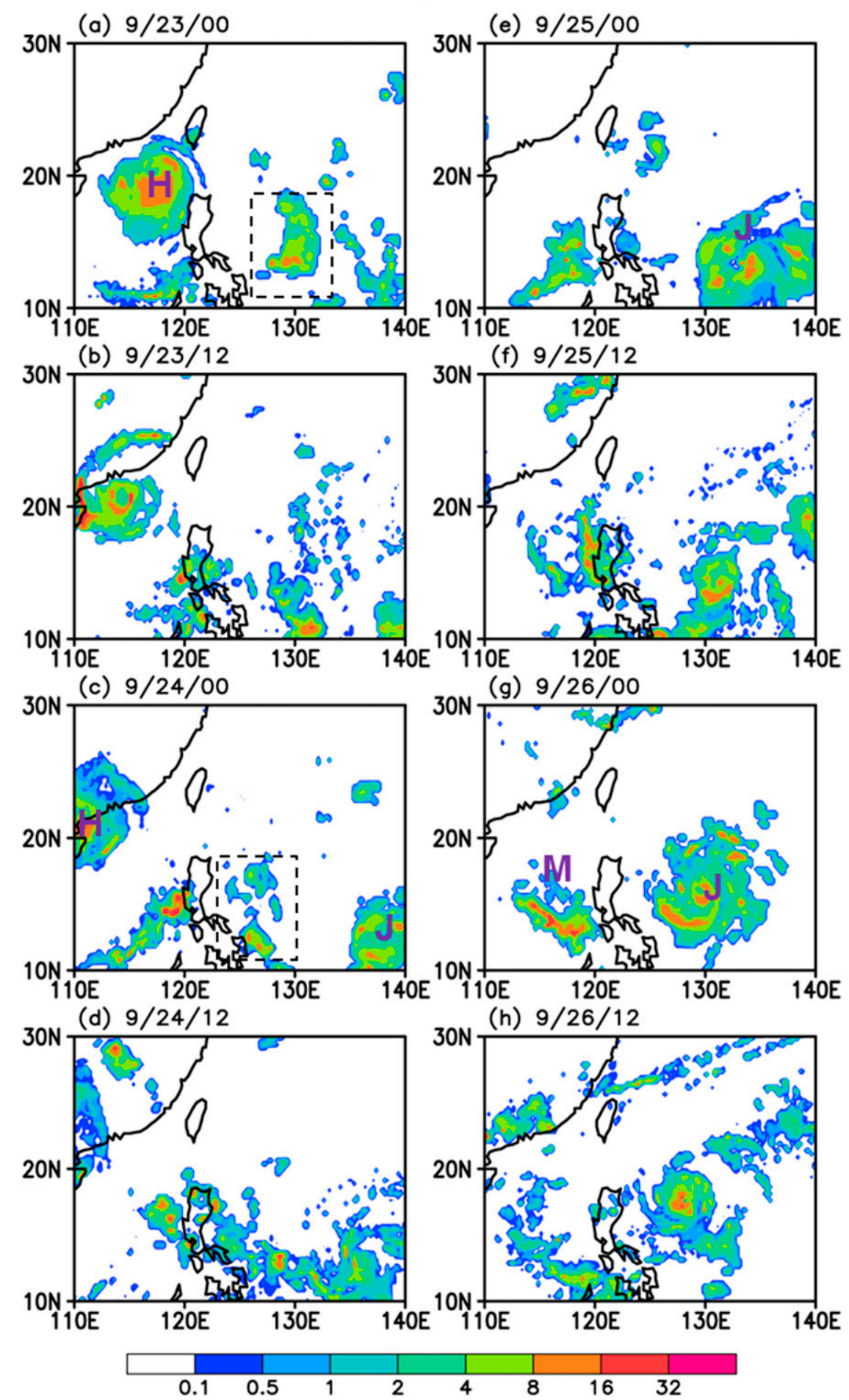

FIG. 4. As in Fig. 3, but for the TRMM 3B42 surface rainfall $\left(\mathrm{mm} \mathrm{h}^{-1}\right.$, shading) from the TMPA dataset. 

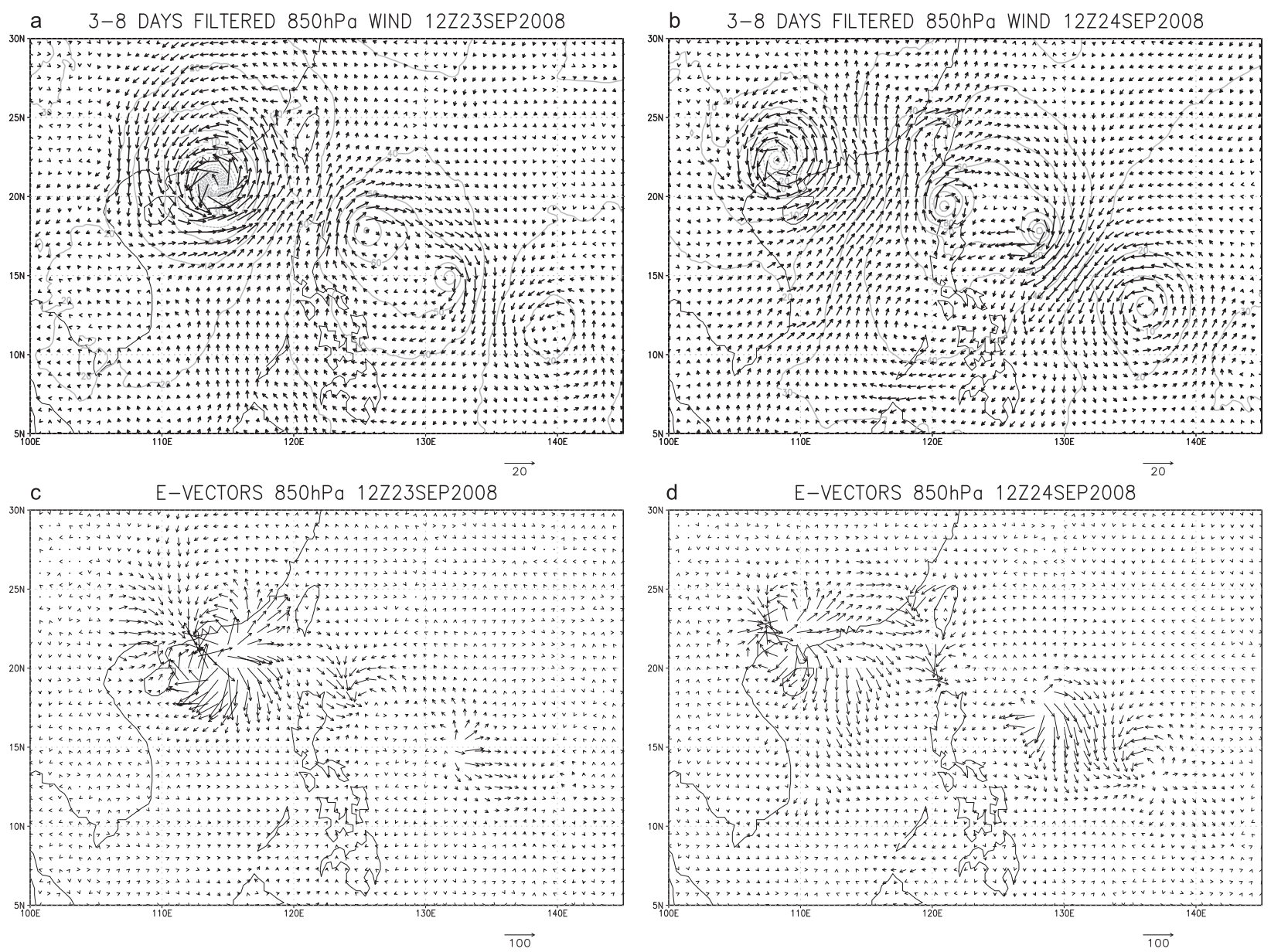

FIG. 5. Synoptic-scale (3-8-day filtered) 850-hPa wind vectors and geopotential heights (m) at (a) 1200 UTC 23 Sep and (b) 1200 UTC 24 Sep and (c),(d) the corresponding $\mathbf{E}$ vectors for the synoptic-scale wave activity.

Li et al. 2006). Carr and Elsberry (1995) showed that the sudden northeastward movement of a TC may be accompanied by Rossby wave energy transmission southeastward that will produce a synoptic-scale wave train. The Rossby wave trains induced by a pre-existing TC are oriented in a northwest-southeast direction, with alternating anticyclonic and cyclonic circulations ( $\mathrm{Li}$ and $\mathrm{Fu} 2006$ ), and TC formation is favored in the trailing cyclonic circulation of the wave train. Li et al. (2006) also demonstrated the importance of the mean monsoon flow in leading to TC development in the Rossby wave train. As both Carr and Elsberry (1995) and Li et al. (2006) noted, the impact of the Rossby wave dispersion on a new TC formation may also depend on background dynamics related to an intraseasonal oscillation.

The 850-hPa wind fields for 23 and 24 September filtered at 3-8 days (Figs. 5a and 5c) reveal a wave train that was oriented in a northwest-southeast direction with alternating cyclonic and anticyclonic perturbations. Whereas Typhoon Hagupit and the developing Jangmi disturbance were located in the cyclonic perturbation regions, the pre-Mekkhala disturbance was in an anticyclonic region of the wave train. Following Trenberth (1986), energy propagation vectors (E vectors) were also calculated (Figs. 5b,d). Note that $\mathbf{E}=\left[\left(-u^{\prime} u^{\prime}+v^{\prime} v^{\prime}\right) / 2,-u^{\prime} v^{\prime}\right]$, where $u^{\prime}$ and $v^{\prime}$ are zonal and meridional components of synoptic-scale wind perturbations, respectively. Rossby wave-type energy dispersion through the boundary between the anticyclonic and cyclonic circulations on both 23 and 24 September is clearly favorable for the formation of Jangmi. This RWD is consistent with the organization of the convection in the pre-Jangmi disturbance on 23 September (Figs. 3a,b) within the cyclonic perturbation as in Fig. 5a, which was farther east than the pre-Mekkhala disturbance (TCS46). This positive RWD effect on the developing Jangmi corresponds with the discussion in a recent study by Xu et al. (2013).

By contrast, the development of pre-Mekkhala disturbance may have been inhibited to some extent by being in the anticyclonic region of the RWD wave train, 
which may have induced downward motion and suppressed convective activities. A natural question is then how the heavy precipitation (Figs. 4c,d) and low-level vortex elements (Figs. 3c,d) could have developed off the east coast of the Philippines on 24 September (section 4a). It is proposed based on Fig. 4 that an interaction between the northeasterlies in the northwest quadrant of Jangmi with the MJO induced large-scale southwesterlies (Figs. 3c,d), which led to an overall increase of convergence over the Philippine Sea, and thereby enhanced the convective processes (Figs. 4c,d) and the spinup of vortex core $\alpha$ (Fig. 4e).

Thus, the Typhoon Hagupit-induced RWD is considered to have both positive and negative impacts on the Mekkhala formation. The negative influence was to induce an anticyclonic environment where the preMekkhala disturbance existed. The positive RWD influence was to contribute a favorable cyclonic environment for the development of Typhoon Jangmi in such a position that northeasterly flow over the Philippine Sea was opposing the southwesterly monsoon flow. This convergence then contributed to the initial evolution of the vortex core $\alpha$. While mesoscale convective heating over the Philippine Sea may have contributed to the initial vortex formation, some other unique mesoscale convections that interacted with the Philippine islands also made contributions to the formation over the South China Sea, which will be described in the next section.

\section{Contribution from diurnally evolving MCSs}

One of the hypotheses tested during TCS-08 was that the existence, the location, and timing of MCSs determine TC formation within a favorable monsoon environment or other precursor synoptic circulations (Elsberry and Harr 2008). Bister and Emanuel (1997) and Ritchie and Holland (1999) have previously emphasized the role of the mesoscale convective vortex (MCV) in the midtroposphere that is created in the stratiform cloud region due to heating above and cooling below the freezing level. Many recent studies with highresolution numerical models (e.g., Hendricks et al. 2004; Montgomery et al. 2006) and recent field experiment observations (Houze et al. 2009; Bell and Montgomery 2010) have highlighted the role of the convective precipitation region of the MCSs in TC formation, and especially a convective tower with positive vorticity that is called a vortical hot tower. Because of significant latent heating via condensation and latent heat of fusion due to freezing of cloud particles, potential vorticity is generated predominantly at low to midlevels. Accordingly, the importance of observing the evolution and structure of MCSs has been well emphasized to enhance our understanding of TC formation process in favorable synoptic environments that may also be modulated by active phases of the intraseasonal oscillation as in section 4 .

\section{a. Diurnal evolution of MCSs during formation (24-27 September 2008)}

When the strong large-scale southwesterlies are present over the South China Sea owing to the eastward movement of the MJO over the western North Pacific (section 4), the primary area in which most of the MCSs and heavy precipitation originate is upstream and over the Philippines (Hoyos and Webster 2007; Ho et al. 2008; Park et al. 2011). Based on an analysis of eight years of TRMM PR rain rates, Ho et al. (2008) found out that the diurnal maximum of rainfall during the WWB period occurs in the late morning. This peak rainfall is attributed to an organized oceanic convective system that develops in a region of maximum low-level convergence upstream (west) of Philippines. Over the Philippines, the secondary peak of rainfall was in the late evening, and originated from afternoon convective activities (Ho et al. 2008). In each of the above studies, large-scale, low-level westerlies existed, but TC formation did not occur. The focus of this subsection is an examination of the change in the diurnal variation of convection that characterized the formation of the pre-Mekkhala depression.

On 24 September (3 days prior to the formation of the pre-Mekkhala depression), the initial low-level vorticity elements were forming over the Philippine Sea (dashed box in Fig. 3c) during the morning (0000 UTC). Thus, the convective processes over the South China Sea would not be expected to be related to the TC formation process. Indeed, the diurnal evolution of convection throughout the morning and afternoon appears to correspond with the climatological diurnal variation of rainfall during a WWB as in Ho et al. (2008). In the morning (0000 UTC, 0800 LT in Fig. 6a), convective processes are relatively suppressed over the Philippines, but convection over the South China Sea is apparent. In particular, the oceanic MCS (indicated as "a" in Figs. 6a,b) that was initiated off the west coast of Philippines earlier in the morning had maximum organization at 0800 and 1100 LT. These kinds of offshore MCSs were found by Ho et al. (2008) to produce the late-morning maximum in rainfall. During the afternoon (1400 and 1700 LT; Figs. 6b-d), the MCS gradually dissipated as it moved westward toward the central South China Sea. The mechanism for the diurnal formation/decay of this offshore MCSs system was explained by Park et al. (2011) as being due to two primary factors: (i) diurnally varying, large-scale westerlies that are associated with land surface heating of the Asian continent; and (ii) a local mesoscale diurnal circulation 
Diurnal variation of IR BT (- 3 day)
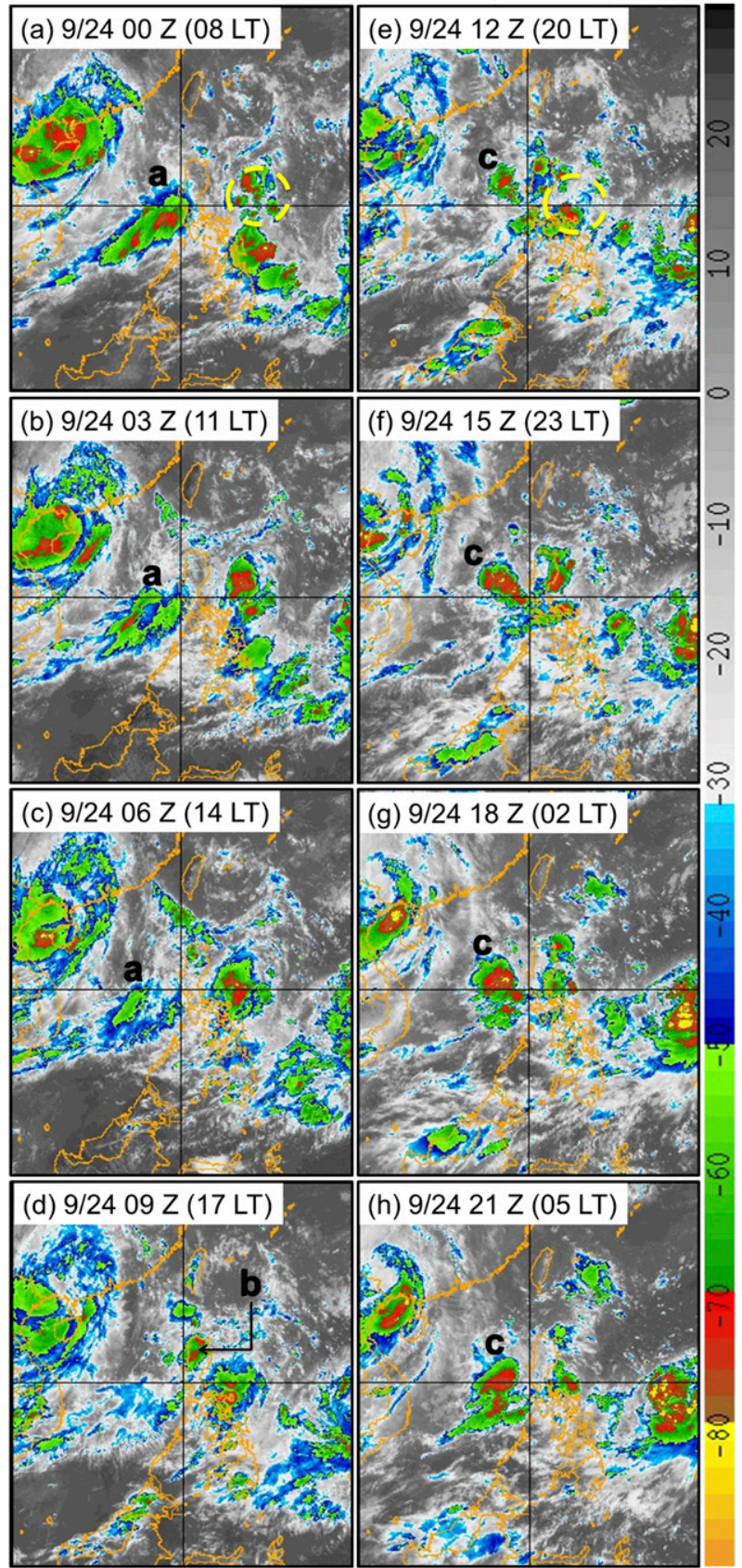

FIG. 6. Diurnal evolution of convection over the South China Sea and the Philippine Sea (crossing lines at $15^{\circ} \mathrm{N}, 120^{\circ} \mathrm{E}$ ) based on 3-hourly variations in MTSAT-1R brightness temperatures from 0800 LT 24 Sep to 0500 LT 25 Sep, which is 3 days prior to the Mekkhala depression formation.

associated with the Philippines [see Fig. 11b of Park et al. (2011)].

Also, the convective processes over the Philippines in the afternoon were also evolving in agreement with the climatological diurnal processes over the highest topography of the northern island of Luzon. The primary MCS developed through 1700 LT ("b" in Fig. 6) and then moved eastward off the coast by 2300 LT (Fig. 6f). Park et al. (2011) explained the strong land heating and local onshore flow lead to the local low-level convergence and create afternoon convection such as the MCS over the Philippines.

Recall that the low-level core vortex of the preMekkhala disturbance (in Fig. 3d) was off the east coast of the Philippines in the late evening of 24 September (Fig. 3d; section 5). Therefore, the convective processes over the Philippines and the South China Sea are then expected to be influenced by the approaching cyclonic vortex. More specifically, that effect is an anomalous diurnal variation of convection beginning at $2000 \mathrm{LT}$ 24 September (Fig. 6e) that then developed into a prolonged convective burst that persisted through 25-27 September (Figs. 7-8). This convective burst ("c" in Fig. 6e) commenced over the northeastern South China Sea and new convective cells at 2300 LT 24 September (Fig. 6f) formed just to the southeast of the prior convection and slightly closer to the coastline. At $0200 \mathrm{LT}$ 25 September (Fig. 6g), the convective system expanded westward, possibly in association with the large easterly vertical wind shear expected during a WWB. Whereas the overall oceanic convection had diminished during the previous afternoon, the convective burst over the eastern South China Sea on 24 September continued through the night and had a maximum horizontal extent at 0800 and 1100 LT (Figs. 7a,b). While this convection weakened, it continued through the afternoon (Figs. $7 \mathrm{c}, \mathrm{d})$. Meanwhile, another MCS commenced over the Philippines between 1400 and 1700 LT ("d" in Figs. $7 \mathrm{c}, \mathrm{d}$ ) and reached maximum intensity at $2000 \mathrm{LT}$ (Fig. 7e) before moving off the west coast of the Philippines at 2300 LT 25 September (Fig. 7e).

Consequently, two primary MCSs " $c$ " and "d" existed over the South China Sea at 2300 LT 25 September (Fig. 7f) with an apparent rotation due to the westward translation of " $\mathrm{d}$ " on the north side and eastward translation of "c" embedded in the WWB on the south side. Note that the core vortex within the pre-Mekkhala circulation (Fig. 3f; section 5) to the east of the MCS "d" was also moving across the Philippines, which is considered to be a critical event to change the ordinary WWB event into a TC formation case. Thus, by 0500 LT 26 September (2100 UTC 25 September, Fig. 7h), the oceanic MCS "c" had developed into an intense convective burst with a spiral rainband to the south that implies a stronger cyclonic circulation (Fig. 7g).

As shown in Fig. 8, this convective burst persisted during 26-27 September over the South China Sea through a merger with another MCS " $c_{1}$ " (Fig. 8b) from 


\section{Diurnal variation of IR BT (- 2 day)}
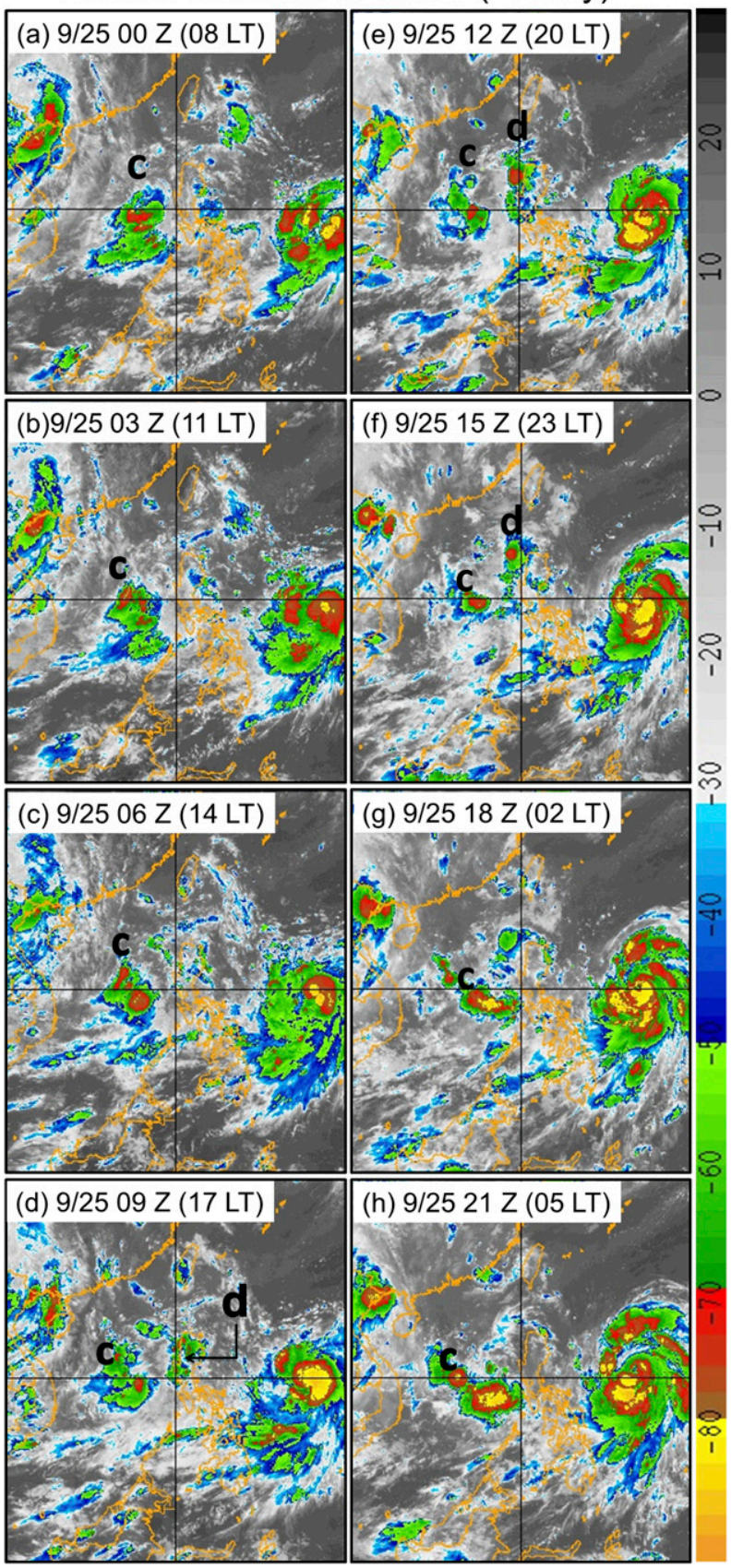

FIG. 7. As in Fig. 6, but from 0800 LT 25 Sep to 0500 LT 26 Sep. Note that Tropical Storm Jangmi is approaching on the right side.

the north. This long-lived, convective burst " $c$ " is considered to provide the critical diabatic heating leading to the formation of the monsoon depression circulation that later became Tropical Storm Mekkhala. At the end of 26 September (Fig. 8h), the long-lasting convective burst is very linear due to the spiral rainband, and seems to be on the periphery of the circulation.
On 27 September (Fig. 9), the spiral rainband feature (as in Fig. 8h) gradually diminished until 0600 UTC (1400 LT). Then, a large convective cell $\left(\mathrm{c}_{2}\right)$ develops close to the coast of Vietnam on the western side of this circulation (Fig. 9d) and then becomes the dominant center of the storm (Figs. 9d-h), possibly via some contribution from another land-originated convective system "e" over Indochina in the afternoon (Figs. 9d,e). The transition of the pre-Mekkhala center was also confirmed by the TRMM observations (not shown). As in Fig. 9g, a quasi-circular convection is roughly collocated with the low-level circulation center by 1800 UTC 27 September, which is tropical depression declaration time according to the RSMC best track.

In summary, two major, active mesoscale cloud clusters ("c" and "d" in Fig. 7) developed over the South China Sea under the influence of the approaching, low-level cyclonic circulation of the pre-Mekkhala disturbance. The first MCS ("c") that originally moved off the coast of the Philippines did not decay in the afternoon and remained very active. A second MCS ("d") that originated over the Philippines and moved over the South China Sea then interacted with the oceanic MCS. The prolonged convective cluster "c" (Figs. 7-9), in cooperation with two additional oceanic convective systems from the north or the west (" $c_{1}$ " and " $c_{2}$ " in Figs. 8-9), is considered to have a critical role in spinning up of the low-level vortex over the South China Sea.

\section{b. Structure changes in the oceanic convective system from the TRMM observations}

Although the half-hourly infrared satellite observations (Figs. 6-9) resolve the diurnal evolution and decay of the convective and mesoscale processes, this narrowband infrared radiance is being emitted from the cloud tops. By contrast, microwave channels reveal the inner structures of the convection. In particular, the passive microwave PCT at $85 \mathrm{GHz}$ provides information about the accumulated effect of ice particles (Mohr and Zipser 1996). As ice scattering reduces the observed brightness temperatures, the PCTs have low values for optically dense ice particles (Park et al. 2007). In general, PCTs at $85 \mathrm{GHz}$ less than $250 \mathrm{~K}$ are considered to be due to significant ice scattering (Spencer et al. 1989). In addition, active microwave measurements provide the vertical distribution of water and ice particles (Iguchi et al. 2000). Many studies (e.g., Petersen and Rutledge 2001; Park et al. 2007) have utilized the TRMM observations (e.g., TMI PCT and PR reflectivity) to understand the variability of convective structures over tropical oceans. Whereas the TRMM observations have been used for some studies of mature tropical cyclones (e.g., Hence and 

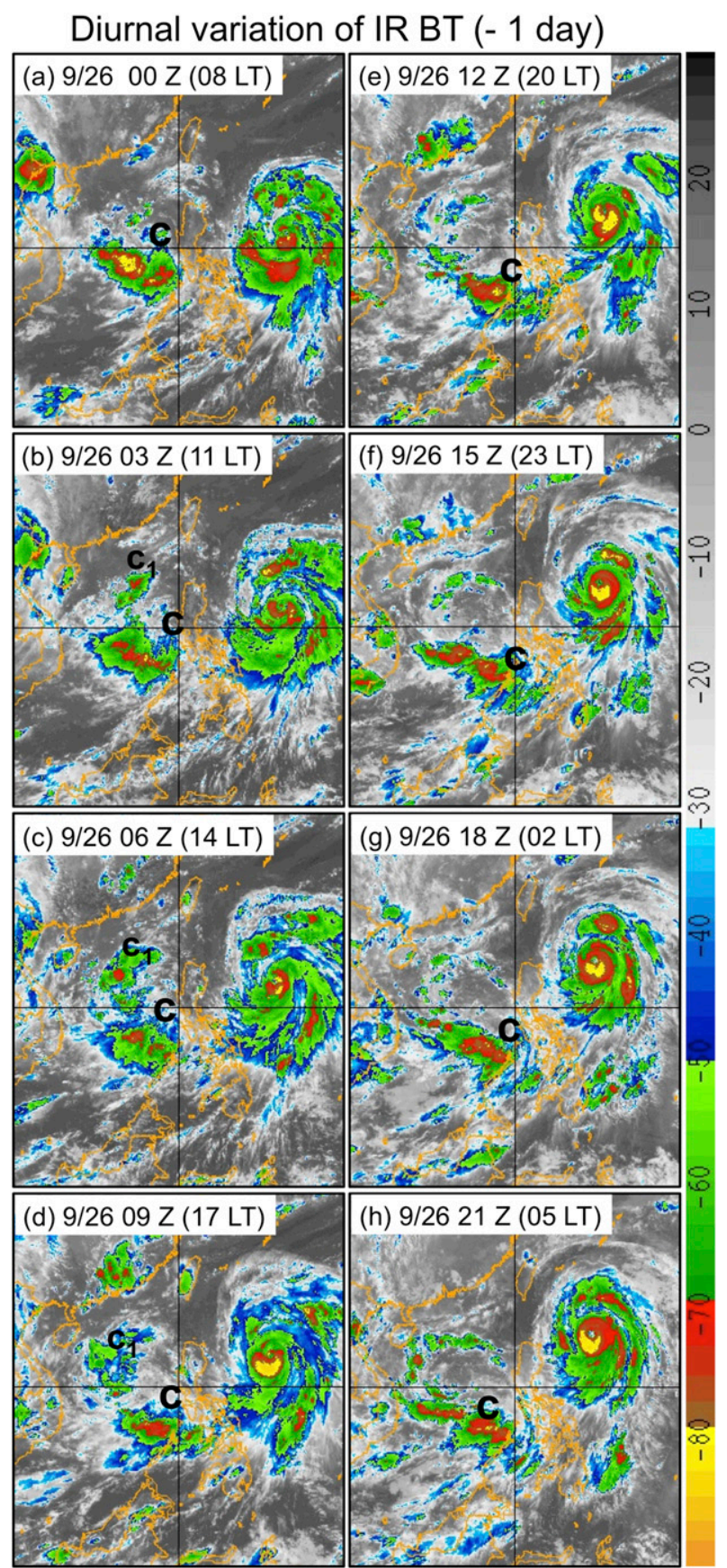

FIG. 8. As in Fig. 6, but from 0800 LT 26 Sep to 0500 LT 27 Sep.

Houze 2012; Jiang et al. 2013), the focus here is on the formation stage.

In this section, the structural changes of the prolonged cloud cluster "c" illustrated in Figs. 8-9 will be examined with three sets of TRMM observations. The first TRMM observation (orbit number 61886) of the cloud cluster in the middle of South China Sea was around 1200 UTC 25 September (Fig. 10), which corresponds well with the MTSAT observation time in Fig. 7e. The second and third TRMM observations (orbit numbers 61901 and 61907 in Figs. 11 and 12) were around 1200 and 2000 UTC 26 September, which corresponds to the MTSAT observations in Fig. 8e and Fig. 8h, respectively. Since the first TRMM observation into the cloud cluster "c" was obtained several hours prior to interacting with another primary MCS "d" (that originated from the Philippines), comparison among the three TRMM observations will show how land-originated convective process contribute to changes in convection structure.

The first TRMM observation indicated that few smallscale convective towers and an extensive stratiform precipitating cloud existed, which implies an ordinary MCS structure. Although several high PR reflectivity elements with reflectivities $>36 \mathrm{~dB} Z$ were observed at 6-km height (Fig. 10a), only few convective regions extended above $12 \mathrm{~km}$ (Fig. 10b). One of the highest convective towers was near $14.4^{\circ} \mathrm{N}, 116.5^{\circ} \mathrm{E}$ with a $85-\mathrm{GHz}$ PCT as low as $160 \mathrm{~K}$ (Fig. 10d). As indicated in the cross section in Fig. 10e, the convective towers (distance $\sim 310 \mathrm{~km}$ ) were as high as $14 \mathrm{~km}$ with an extended stratiform precipitation region to the west (with the bright band near the melting layer). According to Jiang et al. (2013), overshooting cloud towers that reach the tropopause can be approximately defined by any 30-dBZ echoes in the TRMM PR data that are above $14 \mathrm{~km}$. However, these convective cells during this preformation period on 25 September (Fig. 10b) did not penetrate to the tropopause, and the horizontal scales of the convective towers were about 10-20 km (Fig. 9e), which is on the meso- $\gamma$ scale. There existed other deep convective cells to the northwest. However, the horizontal scales in the convective region are similarly small, and the distance between the deep convective regions is relatively far each other. Thus, no evidence of formation was revealed from the TRMM observations of the structure of the oceanic convection on 25 September.

Recall this cloud cluster "c" then interacted with the inland-originated MCS and further intensified until 2100 UTC 25 September (Figs. 7e-g, section 6a). On 26 September, the convective cluster again interacted with another MCS (" $c_{1}$ ") that formed in the middle of South China Sea (Figs. 8b-e), and continued to intensify. Consequently, the prolonged convective burst was radically changed as detected in the next TRMM overpass around 1200 UTC 26 September (Fig. 11) with deeper, larger convective precipitation towers, and an older stratiform precipitation cloud region is displaced downstream. That is, the convective towers along $12.85^{\circ} \mathrm{N}$ between $112.5^{\circ}$ and $113.2^{\circ} \mathrm{E}$ became extremely deep in about $24 \mathrm{~h}$, as the PR storm heights were above $14 \mathrm{~km}$ (Fig. 11b), VIS IR BT $<196$ K (Fig. 11c), and TMI 85-GHz PCT $<165$ K 
Diurnal variation of IR BT (0 day)
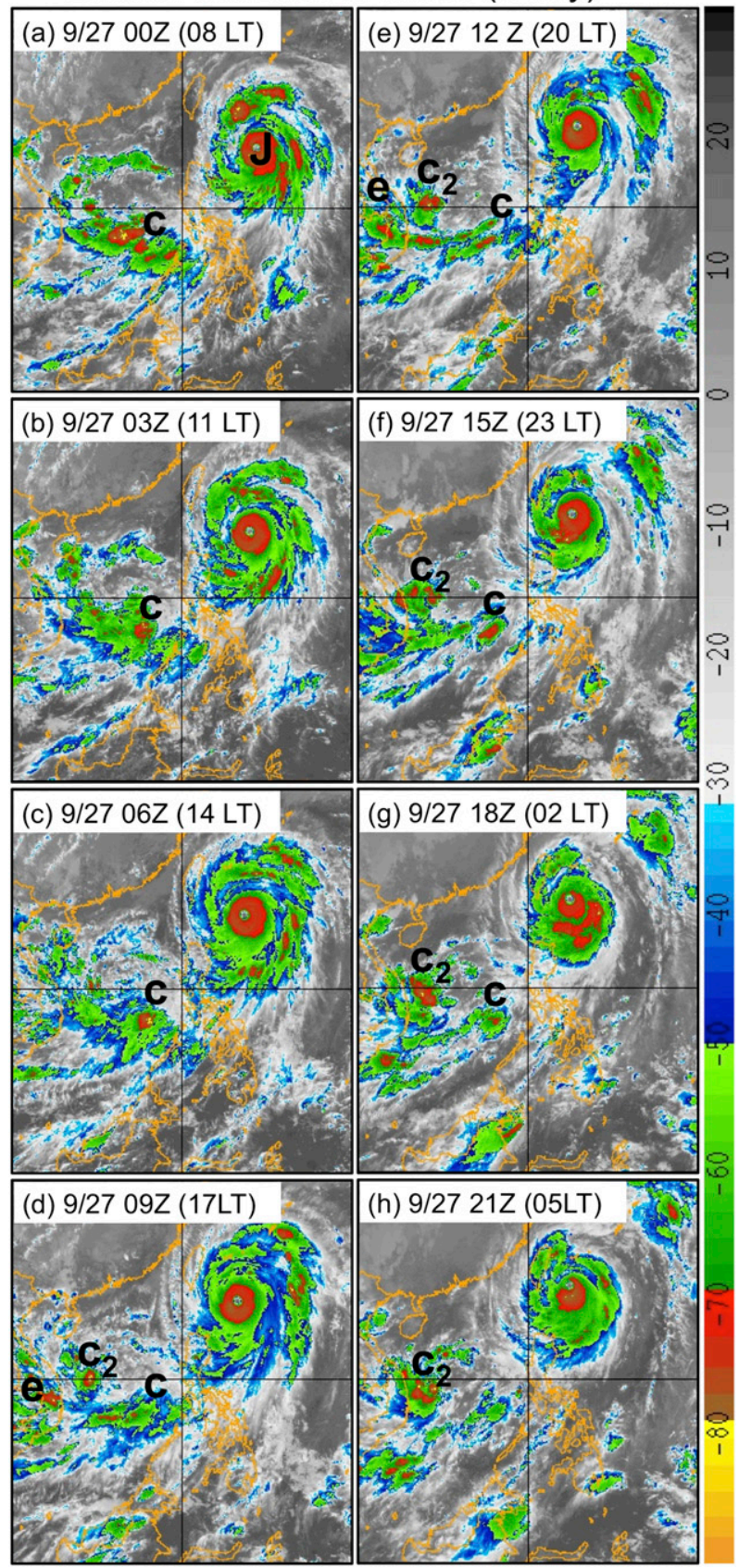

FIG. 9. As in Fig. 6, but for 0000 UTC 27 Sep, which corresponds to local times of 0800 LT 27 Sep-0500 LT 28 Sep on the day of the tropical depression formation.

(Fig. 11d). Furthermore, the 30-dBZ echo was above $14 \mathrm{~km}$, which implies these towers were extending up to the tropopause. The horizontal scales of the convection were about $20-30 \mathrm{~km}$, which is larger than in the first set of TRMM observations in Fig. 10. Since these meso$\beta$-scale convective towers seemed to be very close, it is possible that mergers of the convective towers may have contributed to an upscale process to enhance the systemscale circulation as in idealized numerical simulation by Montgomery et al. (2006).

Recall the convective cluster in Fig. 8h was changed in about $8 \mathrm{~h}$ to have more deeper, larger-scale mesoscale convective towers, which is also revealed in the third TRMM observation (Fig. 12). Elongated, high PR reflectivity cells $>36 \mathrm{dBZ}$ at 6 -km height were observed along latitude $12.85^{\circ} \mathrm{N}$ (Fig. 12a). The TRMM PR storm height data in Fig. 12b indicated that several convective cells between $112.4^{\circ}$ and $14.0^{\circ} \mathrm{E}$ extended up to above $12-14 \mathrm{~km}$, which corresponds with extreme VIS infrared brightness temperatures less than $195 \mathrm{~K}$ (Fig. 12c) and TMI 85-GHz PCTs less than $165 \mathrm{~K}$ (Fig. 12d). The cross section of the TRMM PR observations along $12.85^{\circ} \mathrm{N}$ (Fig. 12e) confirms the existence of multiple deep convective towers extending up to $14 \mathrm{~km}$, which is consistent with the minimum infrared brightness temperature less than $150 \mathrm{~K}$.

The convective structural change leading to the formation of the pre-Mekkhala depression is confirmed by comparison of the PR reflectivity contoured frequency by altitude diagrams (CFADs; Yuter and Houze 1995) for convective rain pixels at the three observations. The CFADs (Figs. 13a-c) show convection features that are overall strong and deep since the major population $(80 \%)$ of reflectivities at $2-4 \mathrm{~km}$ were in the high reflectivity range (30-37 dBZ) and the minor population $(20 \%)$ of the reflectivities extended up to about $10 \mathrm{~km}$. The key change from the first to the second CFADs (CFAD2 minus CFAD1; Fig. 13d) is an increased population of the highest reflectivity range at each level from $4 \mathrm{~km}$ up to $10 \mathrm{~km}$. This elevated reflectivity increase is attributed to the transformation of the typical MCS structure (Fig. 10e) toward a structure dominated by overshooting convective towers (Fig. 11e) due to the impact of the land-originated MCS. Since the increased PR reflectivities in the mid- to upper troposphere may imply enhancement of the precipitation-sized particles (either rain or ice particles), the CFAD2 minus CFAD1 structure (Fig. 13d) may indicate larger latent heating at those levels. By contrast, the primary change in the third PR observation compared to the second one (CFAD3 minus CFAD2; Fig. 13e) is the shift of the low-level peak population into a higher reflectivity range (35-40 dBZ), which suggests that the convective latent heating may have become more concentrated in the lower troposphere. In summary, these PR reflectivity CFADs during $24-47 \mathrm{~h}$ prior to the tropical depression declaration time implies the critical contributions from deep convective regions to the formation, in which the associated latent heating is released in a deep layer from the mid to upper levels down to lower levels. 
61886 2008-9-25 12:35:8 UTC

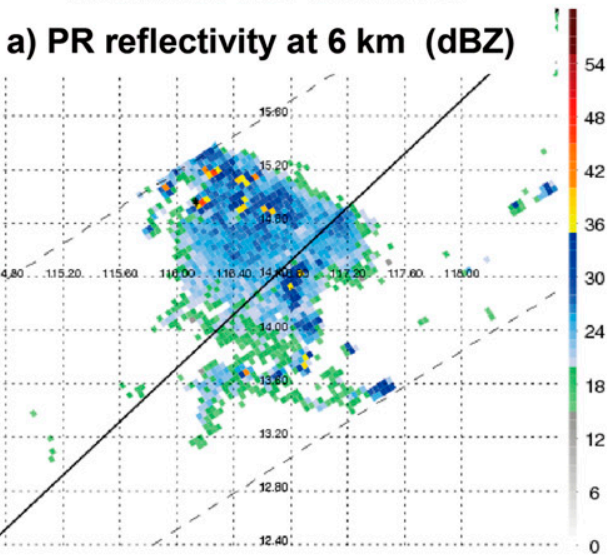

c) VIS IR BT (K)

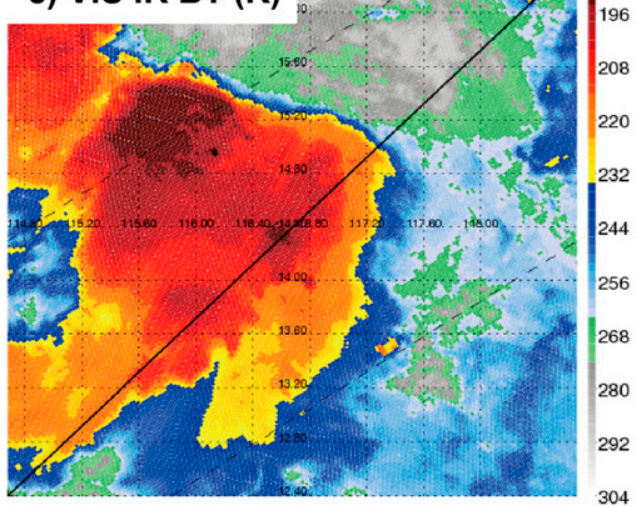

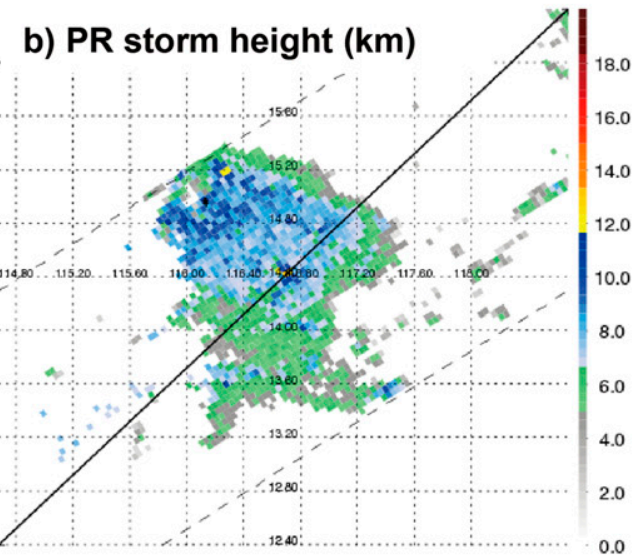

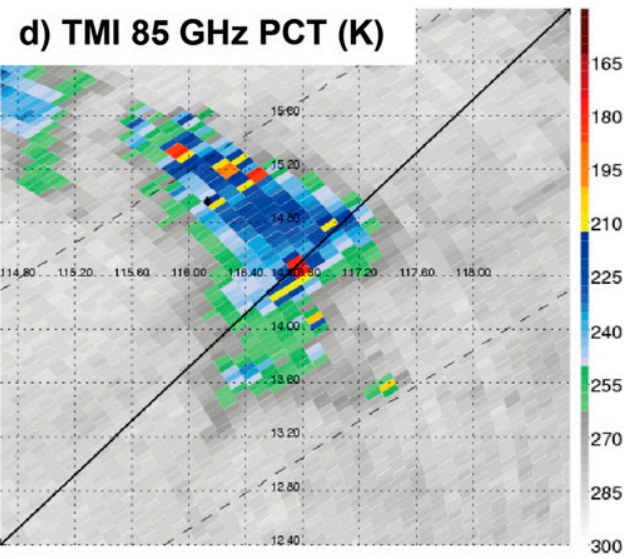

e) cross-section

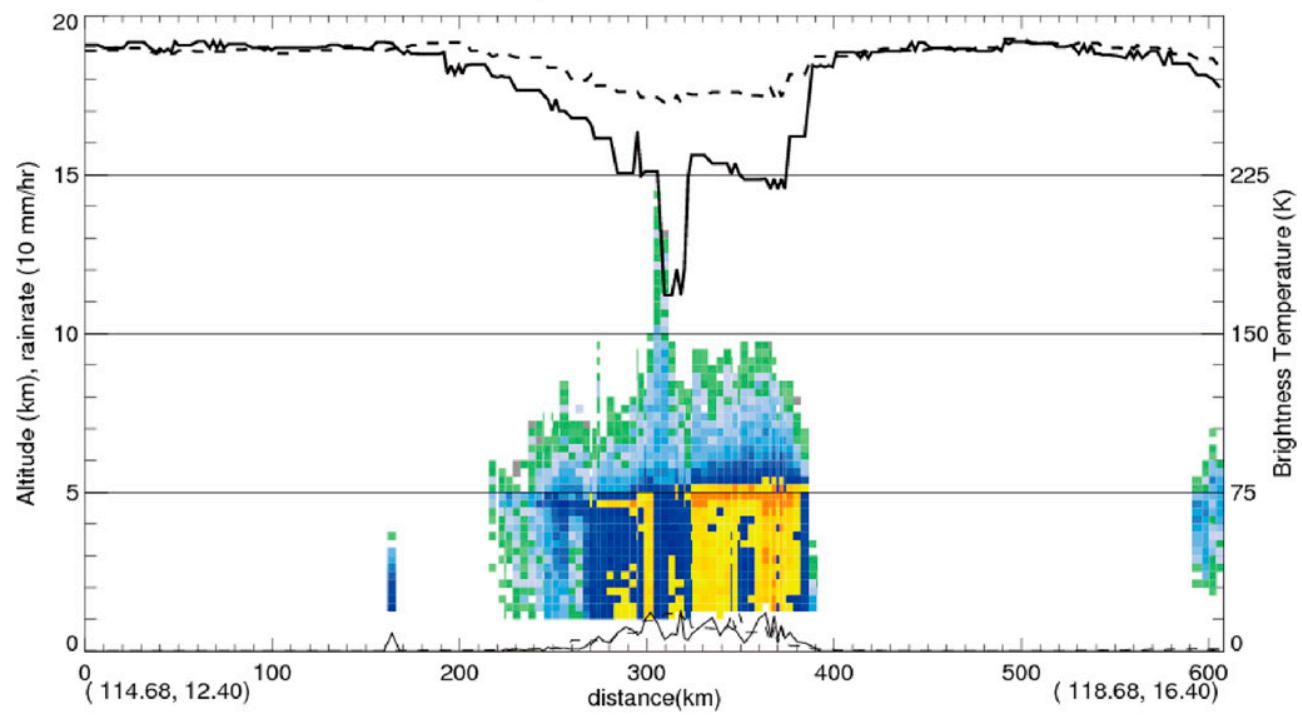

0

6

12

18

24

30

48

FIG. 10. Horizontal distributions from TRMM orbit 61886 at 1235 UTC 25 Sep 2008, which almost corresponds with the MTSAT observation time in Fig. 7b, of (a) PR reflectivity (dBZ) at $6 \mathrm{~km}$, (b) PR storm height $(\mathrm{km}),(\mathrm{c})$ VIS infrared brightness temperature (K), and (d) TMI 85-GHz PCT (K) with LIS lightning flashes (black points) in each panel. (e) Vertical cross-sectional distributions of reflectivity (shading), TMI PCTs at 85 and $37 \mathrm{GHz}$ (thick solid and dashed lines, respectively, with the right axis), and near-surface rain rates from TMI and PR (thin solid and dashed with the left axis in $10 \mathrm{~mm} \mathrm{~h}^{-1}$ unit) along the lines in (a)-(d). 
61901 2008-9-26 11:39:38 UTC

a) PR reflectivity at $6 \mathrm{~km}(\mathrm{dBZ})$
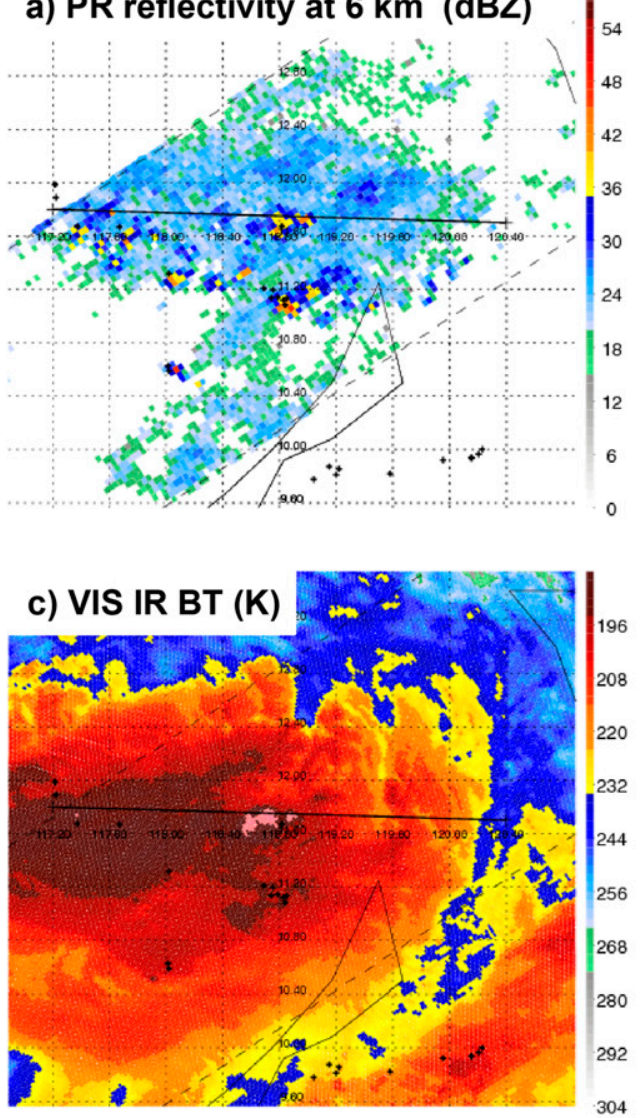
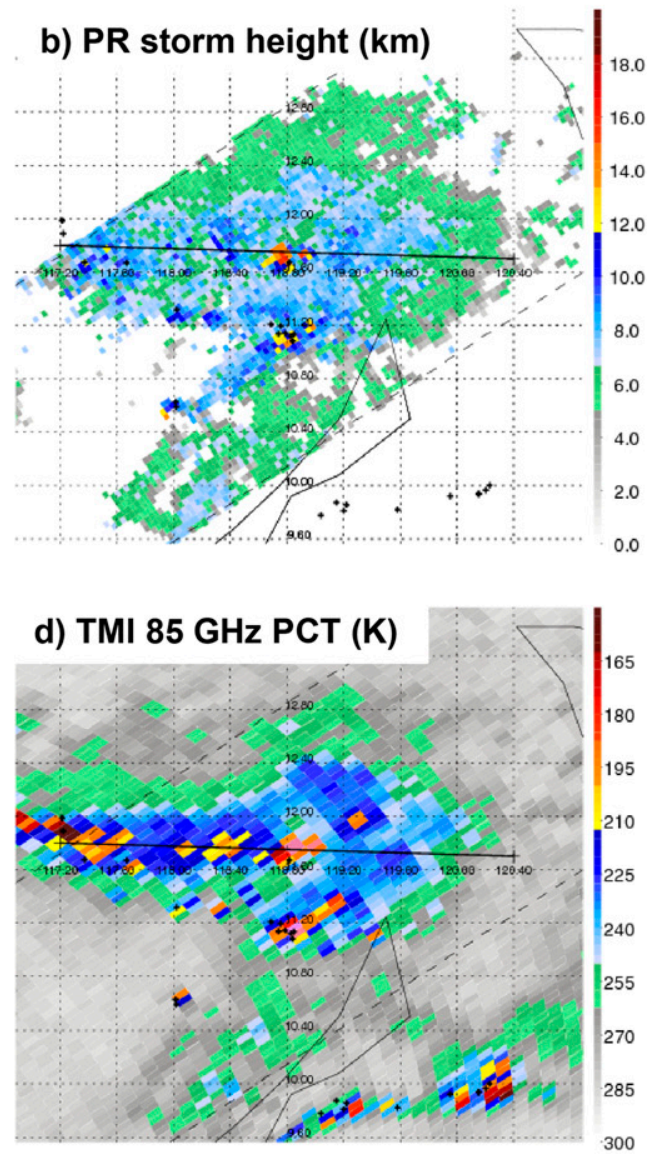

e) cross-section

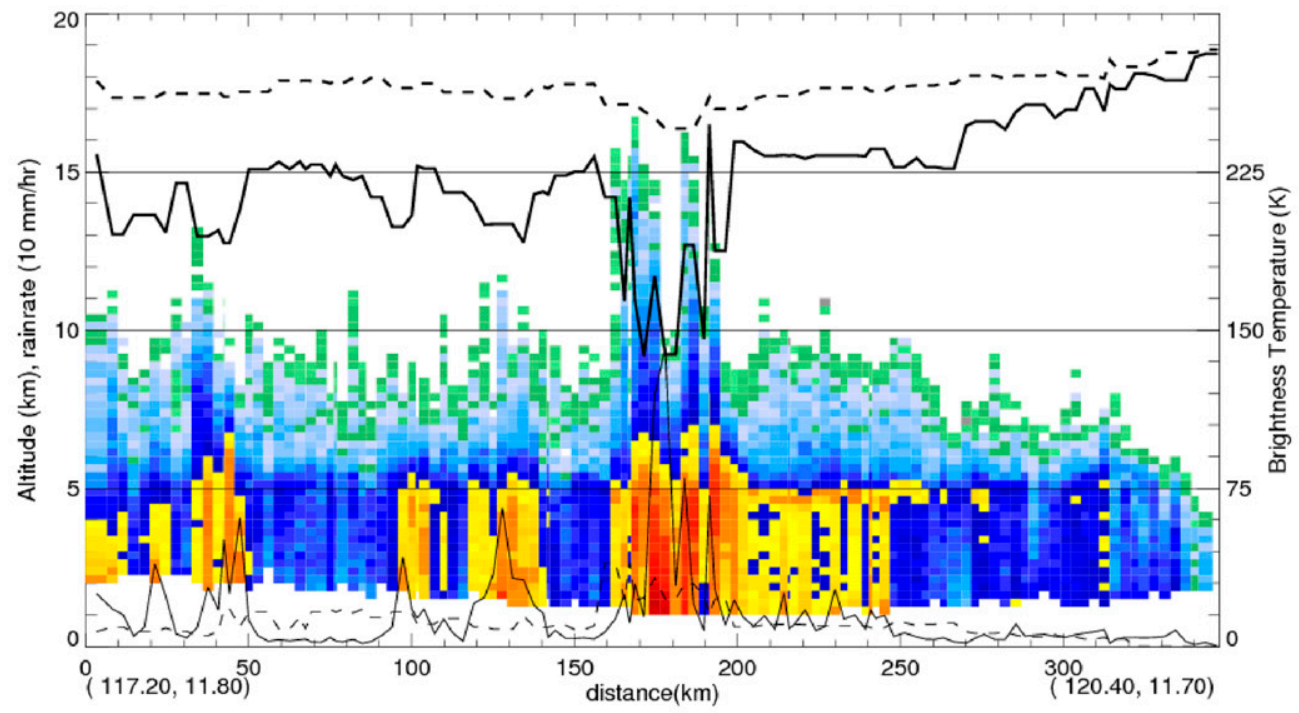

0

$\begin{array}{lll}6 & 12 & 18\end{array}$

$\begin{array}{lll}24 & 30 & 36\end{array}$

42

48

54

FIG. 11. As Fig. 10, but for the TRMM orbit 61901 at 1139 UTC 26 Sep 2008, which almost corresponds with the MTSAT observation time in Fig. 8e. 
61907 2008-9-26 21:29:6 UTC
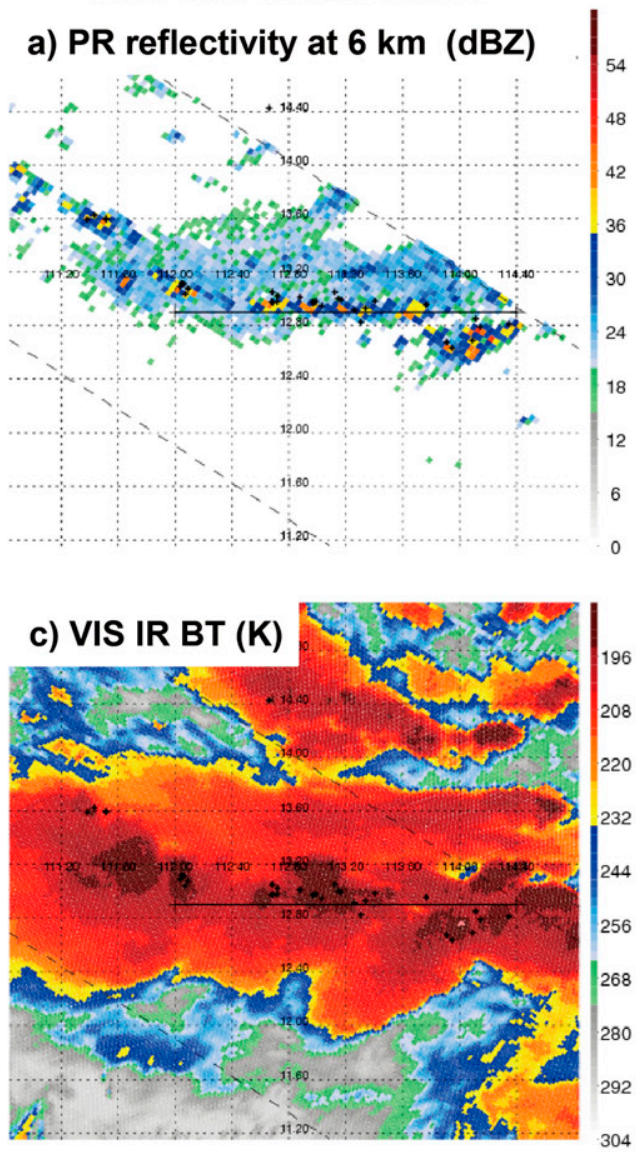

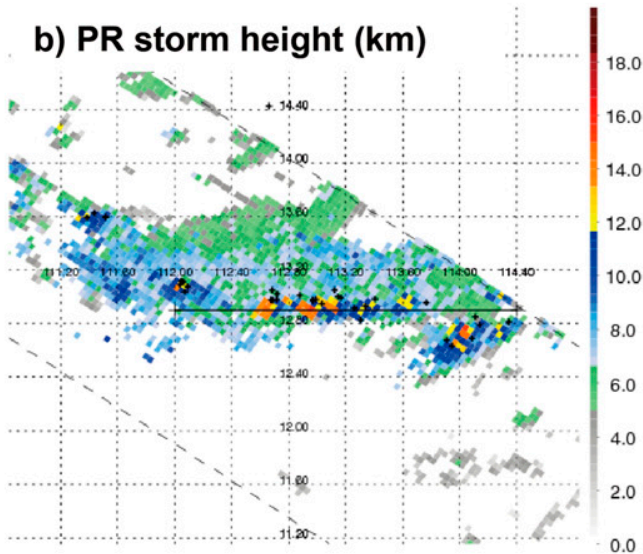

d) TMI 85 GHz PCT (K)

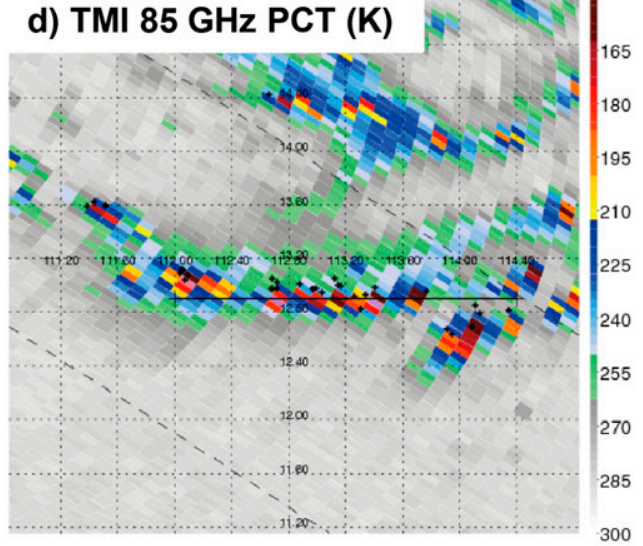

e) cross-section

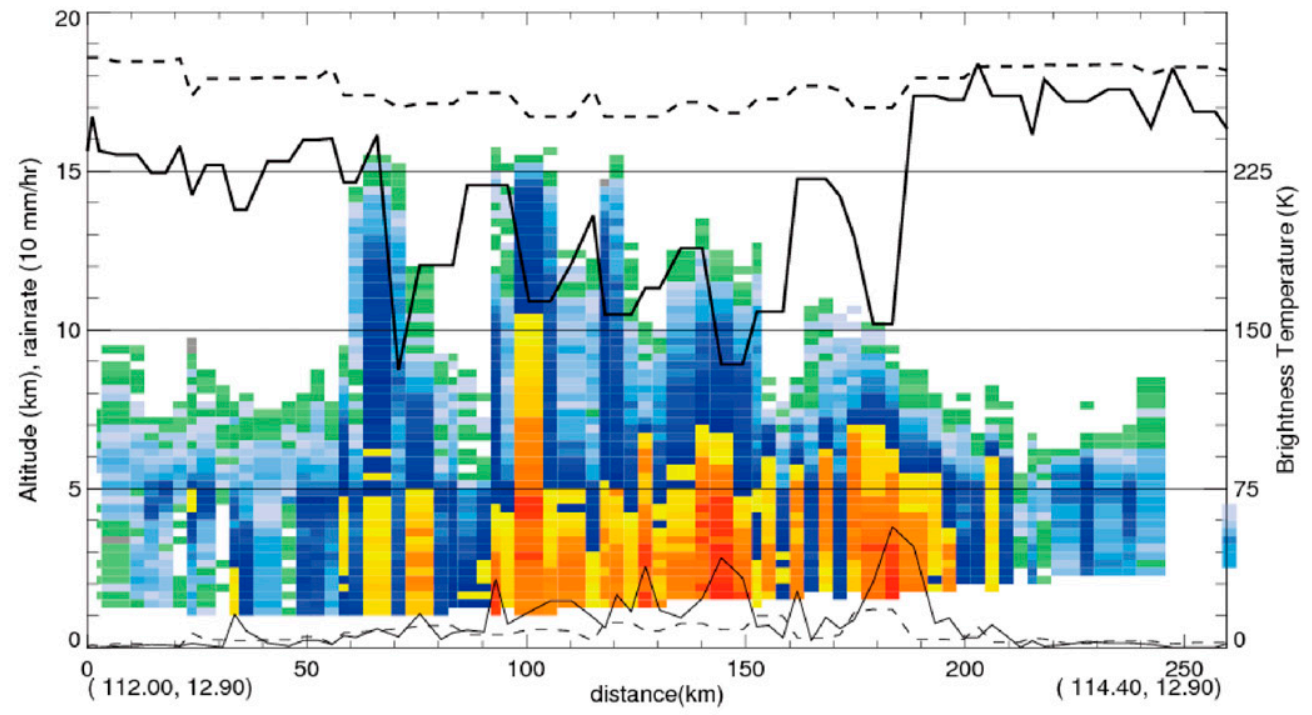

FIG. 12. As in Fig. 10, but for the TRMM orbit 61907 at 2129 UTC 26 Sep 2008. 
(a) CFAD1

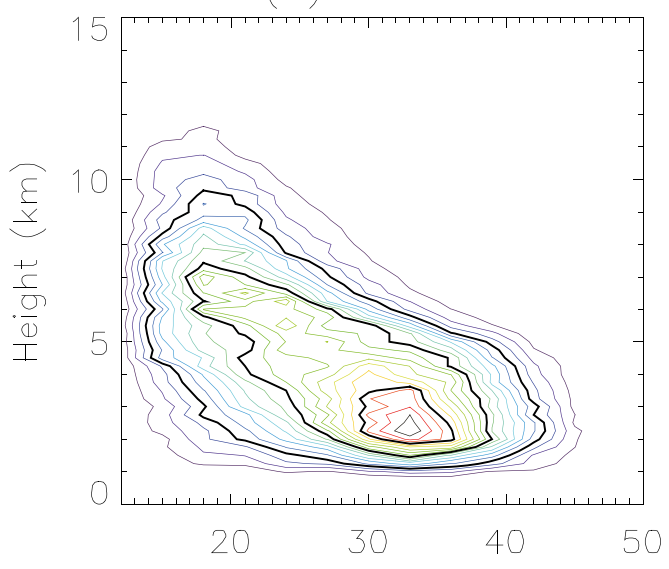

(b) CFAD2

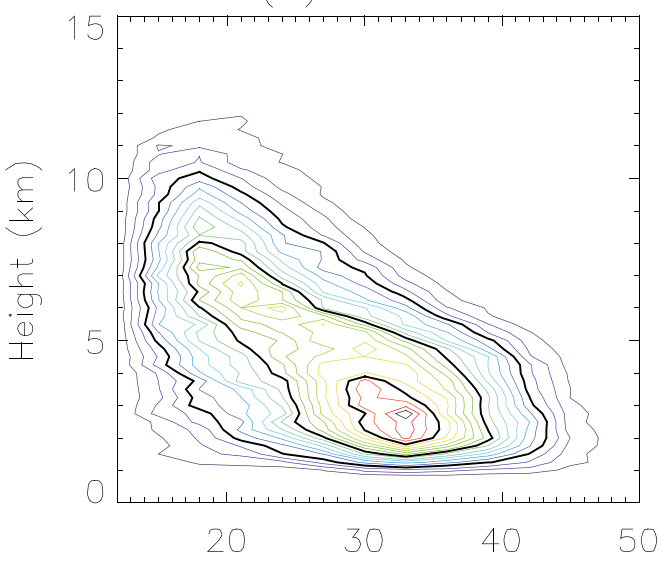

(d) CFAD2 - CFAD 1

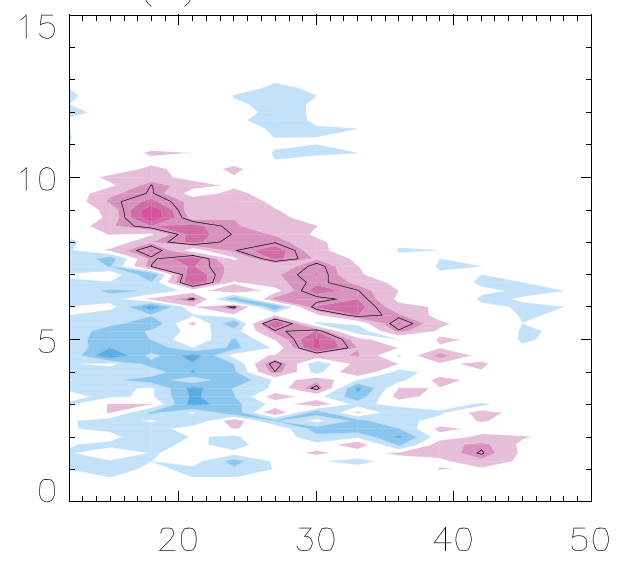

(c) CFAD3

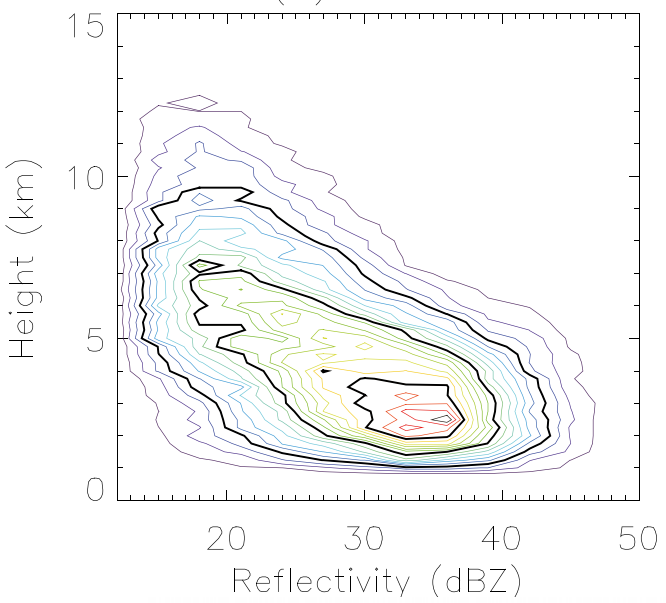

(e) CFAD3-CFAD2
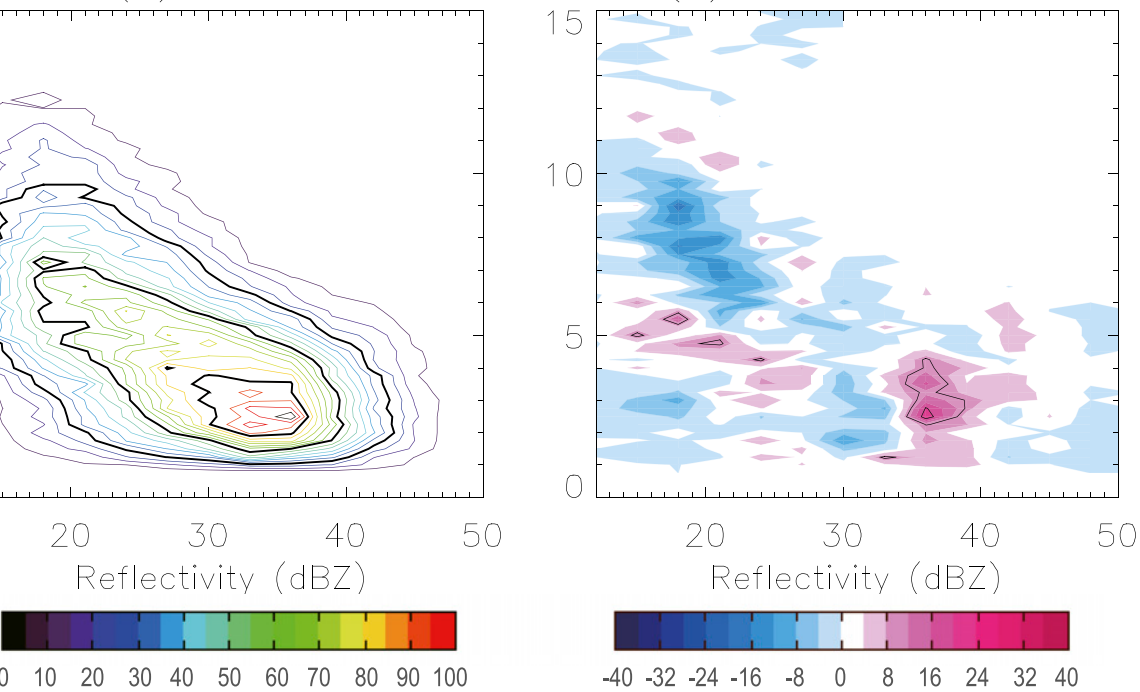

FIG. 13. CFAD1, CFAD2, and CFAD3 of TRMM PR reflectivity data of (a) first, (b) second, and (c) third TRMM orbits passing over the prolonged convective system in Fig. 10e, Fig. 11e, and Fig. 12e, respectively; and (d) CFAD2 minus CFAD1 and (e) CFAD3 minus CFAD2. Contours represent the frequency of occurrence relative to the maximum frequency in the data sample (color contour every $5 \%$ and black contours at $20 \%, 50 \%$, and $80 \%$ ). 

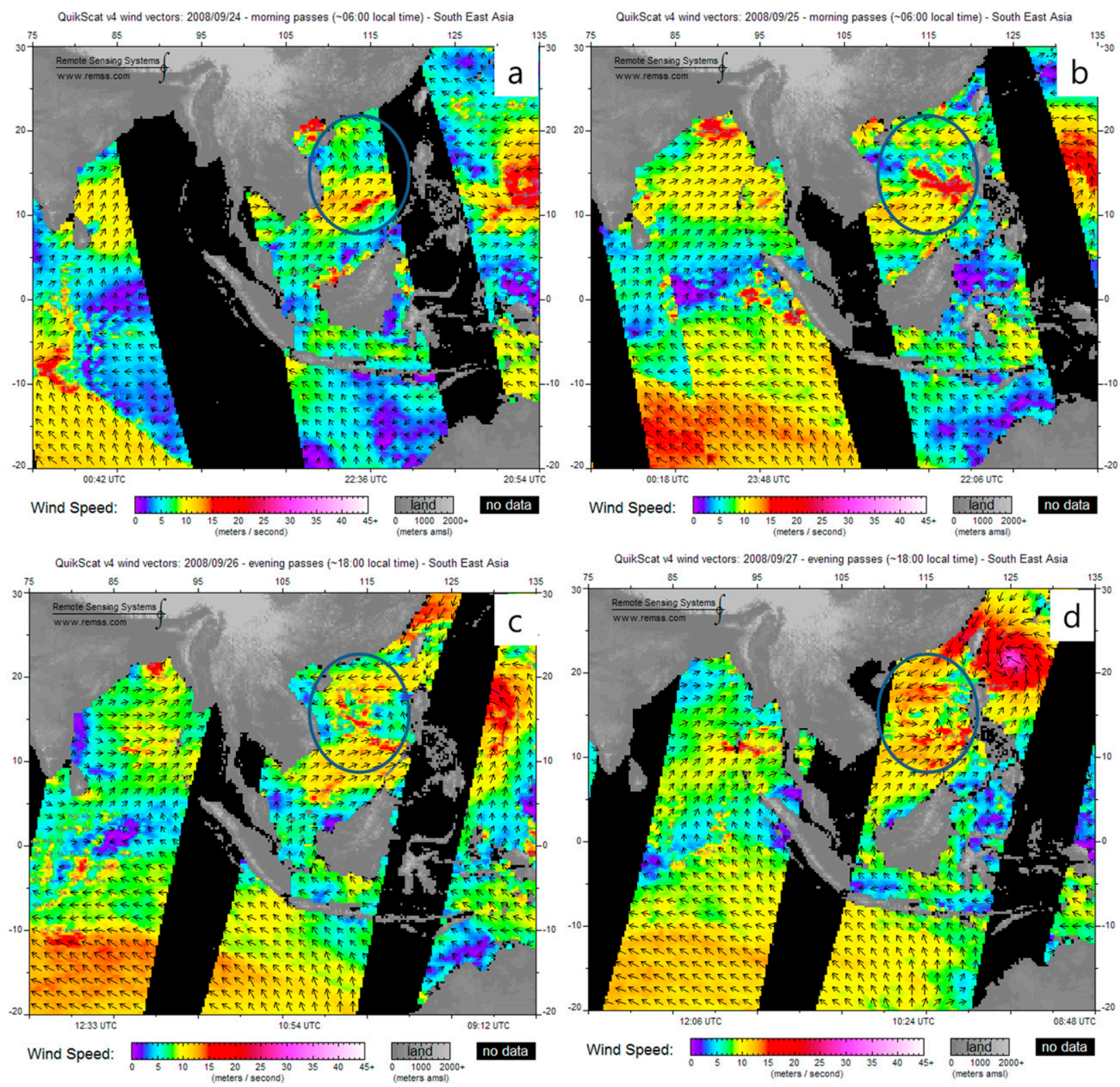

FIG. 14. Sea surface wind vectors and speeds (shading, bar at the bottom) of QuikSCAT morning passes on (a) 24 and (b) 25 Sep 2008 , and evening passes on (c) 26 and (d) 27 Sep 2008. Note in the blue circle (South China Sea) that the open-wave, large-scale westerly wind bursts on 24 Sep in (a) evolved to a closed surface cyclonic circulation of pre-Mekkhala tropical depression on 27 Sep in (d). Figures were obtained from Remote Sensing Systems (www.remss.com).

Associated with the structural change in the prolonged convective cluster on 25-26 September, the critical changes in the sea surface winds over the South China Sea were as detected by QuikSCAT observations (Fig. 14). On 24 September, large-scale southwesterlies were present over the South China Sea in association with phase 6 of the MJO (Fig. 2). After vortex core $\alpha$ (Fig. 3) arrived at the east coast of the Philippines on 25 September, the oceanic convection that originated off the west coast of the Philippines did not decay; rather, it was prolonged beyond the regular diurnal cycle until the evening due to interactions with the inland-originated convection. This prolonged convective cluster on 25-26 September then had multiple deeper, larger, multiple convective towers, and thus the net heating may have contributed to the system-scale secondary circulation via a process akin to the Eliassen (1951) balanced vortex response to a heat source. Accordingly, a closed surface cyclonic circulation (Fig. 14d) was induced over the South China Sea on 27 September that became the pre-Mekkhala tropical disturbance. 
TABLE 1. Two critical steps for the Mekkhala formation were the evolution of the initial low-level vortex core to the east of the Philippines on 25 Sep (step I), and the formation of the well-organized, closed surface cyclonic circulation of pre-Mekkhala depression on 27 Sep (step II). Date (second column) and sequential TC formation processes (third column) leading to the critical steps were divided into (top) the large-scale and synoptic-scale contributions from 22 to 24 Sep over the Philippines Sea and (bottom) the mesoscale contribution from 25 to 26 Sep over the South China Sea.

\begin{tabular}{|c|c|c|}
\hline & Date & Sequential TC formation process \\
\hline $\begin{array}{l}\text { Large- and synoptic-scale } \\
\text { contributions (Philippines Sea) }\end{array}$ & $\begin{array}{l}22 \text { Sep ( }-5 \text { day) } \\
23 \text { Sep ( }-4 \text { day) } \\
24 \text { Sep ( }-3 \text { day) } \\
\text { (Step I) The form }\end{array}$ & $\begin{array}{l}\text { Large-scale southwesterlies increased by MJO phase at } 6 \text { (Fig. 2) } \\
\text { Jangmi developed due to Rossby wave dispersion induced by Hagupit } \\
\text { The interaction between Jangmi and the large-scale southwesterlies } \\
\text { produced low-level vortex core "A" (Figs. } 3 \mathrm{c}, \mathrm{d} \text { ) } \\
\text { ion of the low-level vortex core at the east Philippines ( } 25 \mathrm{Sep} \text { ) }\end{array}$ \\
\hline $\begin{array}{l}\text { Mesoscale contributions } \\
\text { (South China Sea) }\end{array}$ & $\begin{array}{l}26 \text { Sep (-1 day) } \\
\text { (Step II) The forr }\end{array}$ & $\begin{array}{l}\text { The oceanic MCS from the west coast of the Philippines with typical } \\
\text { MCS structure } \\
\text { Under the influence of the approaching low-level vortex, the MCS } \\
\text { prolonged beyond its diurnal cycle and then merged with the normal } \\
\text { afternoon convection originated from the Philippines } \\
\text { The prolonged, oceanic MCS went through the critical convective structural } \\
\text { changes having deeper convective towers with mesoscale (1200 UTC) } \\
\text { and multiple overshooting convective towers ( } 2100 \text { UTC) } \\
\text { tion of a well-organized, surface cyclonic circulation ( } 27 \text { Sep) }\end{array}$ \\
\hline
\end{tabular}

\section{Summary and conclusions}

Since TC formation close to the coastline of the Asian continent presents a significant threat to heavily populated coastal countries, near-coastal TC formation needs to be better understood. The current investigation with high-resolution ECMWF YOTC analyses and multiple satellite observations has elucidated sequential TC formation processes for TC Mekkhala that began over the Philippine Sea [Table 1 (top)] but developed over the South China Sea [Table 1 (bottom)] off the coastline of Vietnam in late September 2008. Interactions among multispatial and temporal scales of tropical circulations have been suggested to explain how an ordinary tropical disturbance (TCS46 during the TCS-08 field experiment) transformed to a warm-core tropical depression after moving across the Philippines.

An active phase of the MJO with a WWB over the Philippine Sea set up the favorable large-scale conditions (section 4). Special locations and timing of Typhoon Hagupit and Tropical Storm Jangmi were the essential synoptic-scale contributions that had preliminary roles in organizing the relatively weak low-level vortex within the pre-Mekkhala tropical disturbance over the Philippine Sea (section 5). However, the diurnally evolving mesoscale convective processes over the South China Sea and over the Philippines within the context of the WWB were critical to first developing a monsoon depression and finally resulting in intensification into a TC (section 6). These analyses have illustrated a process by which mesoscale contributions in association with land interaction may lead to TC formation near the coast. Note such an overland mesoscale convective system contribution differentiates this case from the more common TC formations that only involve atmospheric/oceanic processes over the open sea.

The first critical step for the formation of Mekkhala was the evolution of the initial, weak low-level core vortex at the east of the Philippines on 25 September [step I in Table 1 (top)]. The ECMWF analyses provided the description of the large-scale circulation of the MJO and specifically the role of the large-scale monsoon westerlies on the development of the incipient preMekkhala disturbance. Throughout September 2008, a well-defined MJO propagated eastward from the Indian Ocean to the western Pacific and thus modulated the large-scale circulation over the entire western Pacific (Fig. 1). It is well-known (e.g., Harr and Elsberry 1995; Kim et al. 2011) that the active phase of the MJO provides favorable environmental conditions for TC formation, and the formation of Typhoon Hagupit was no doubt also affected by these favorable conditions. The strong WWB over the Philippine Sea after 22 September during the MJO phase 6 had multiple effects on the formation of Mekkhala.

One of the unique aspects of the initial stage of the preMekkhala development was that the low-level circulation east of the Philippines on 24 September was actually in the anticyclonic flow region of Rossby wave dispersion (RWD) from landfalling Typhoon Hagupit. That is, the preceding Typhoon Hagupit only had an indirect RWD influence on the formation by temporarily inhibiting the development of pre-Mekkhala disturbance (Fig. 5). However, the developing Tropical Storm Jangmi farther 
to the east was in the favorable cyclonic regime of the RWD, and Jangmi had a broad outer circulation as well. It was the northeasterly flow in advance of Jangmi interacting with the enhanced southwesterly flow of the MJOrelated WWB that established the convergence line east of the Philippines within which the initial stage of the preMekkhala development occurred. Accordingly, the net effect of these large- and synoptic-scale circulations is to just produce the incipient, meso- $\alpha$-scale, low-level vortex that crossed the east coast of the Philippines without formation [step I in Table 1 (top)].

Given this special condition of the low-level vortex approaching the Philippines from the east, the critical changes in the evolution of the convection over the South China Sea to the west of the Philippines were revealed by MTSAT-1R observations (Figs. 6-9). The $M T S A T-1 R$ infrared brightness temperatures revealed that the approaching low-level vortex invigorated the normal afternoon convection over the topography to generate an MCS ("d" in Fig. 7). A preceding MCS off the west coast of the Philippines ("c" in Fig. 8) interacts with the large-scale westerlies to generate a rainfall maximum just offshore during the late morning. Then, the invigorated MCS over the topography in the preMekkhala case soon interacted with a prior vigorous oceanic MCS ("c" in Figs. 7e-h) that had not decayed, and thus contributed to the oceanic cloud cluster being prolonged beyond its regular diurnal evolution.

Three timely TRMM observations on 25 and 26 September provided insights into the critical structural changes before and after interacting with the landoriginated MCS. The oceanic MCS was first characterized by few small-scale (meso- $\gamma$ scale) convective towers and an extensive stratiform cloud, which implied an ordinary MCS structure (Fig. 10). The second TRMM observation indicated (presumably due to the interaction with the land-originated MCS) the prolonged convective cluster had a larger (meso $\beta$ ) scale, deeper convective towers that developed up to the tropopause (Fig. 11), which is a favorable factor for initiating vortex spinup (Bell and Montgomery 2010). The third TRMM observation then revealed the existence of multiple, overshooting deep convective towers very close to each other, which is expected to release significant latent heat in the column and lead to the generation of low-level vorticity (Fig. 12). Analyses of the TRMM PR data confirm that convective towers such as in Figs. 11e and 12e may contribute to the development of the system-scale TC circulation. Indeed, the formation of the well-organized, surface cyclonic circulation (Fig. 14d) was well documented by QuikSCAT observations [step II in Table 1 (bottom)].

In conclusion, it is found out that the large-scale environment and synoptic-scale perturbation led to the incipient, weak low-level vortex via a downscale process, and the mesoscale mechanism over the South China Sea and over the Philippines constructed the TC-scale circulation via an upscale process. In particular, the interaction of the two MCSs (originated upstream and over the Philippines) led to the significant structure change of the prolonged convective burst, which implies a critical role of land-interaction mesoscale process leading to near-coast TC formation.

While the current study has inferred the temporal evolution of the vertical structure of the convection that leads to low-level spinup, the limitation of these analyses based on satellite observation is the inability to provide detailed kinematic and dynamic effects from these convective towers. Thus, further studies with aircraft Doppler radar systems are needed as in the Bell and Montgomery (2010) and Park and Elsberry (2013) studies.

During and after the formation of the tropical depression, the ocean heat content (OHC) over the northern South China Sea remained relatively low (not shown) due to the cold wave previously induced by Typhoon Hagupit. While the magnitude of vertical wind shear ( $\sim 10 \mathrm{kt})$ tended to be small on 27 September, the excessive vertical wind shear $(>\sim 25 \mathrm{kt})$ existed temporarily on 28 September due to the approaching Typhoon Jangmi (now shown). While such a low OHC condition, in conjunction with the unfavorable vertical wind shear condition, may have contributed to the delayed intensification of pre-Mekkahala depression on $28 \mathrm{Sep}$ tember, the OHC condition is expected to be less critical during formation stage. The vertical wind shear is the primary environmental control on formation, based on the two-dimensional framework of $\mathrm{OHC}$ and vertical wind shear (Park et al. 2012).

Since 1200 UTC 28 September, the pre-Mekkhala tropical depression intensified further as it approached the east coast of Vietnam. Maximum intensity occurred about $100 \mathrm{~km}$ off the coast. It is speculated based on the MTSAT imagery that convection over the topography of Indochina Peninsula may have then contributed to the system intensification. However, to fully understand the influence of land-interacted MCSs to the developing Mekkhala, further analysis of the convection and circulation is necessary.

Recognition of the formations such as Tropical Storm Mekkhala (2008) might be improved if the forecasters are aware of anomalous signals in diurnal evolution and characteristics of convections (section 6), especially in other coastal regions where TC formations are possible. If an anomalous feature in the diurnal variation of convection (e.g., prolonged convective burst) is detected, it may indicate an enhanced possibility of the formation, 
especially if the convective towers are anomalously deep and have some indication of cyclonic circulation. Currently, regional model sensitivity tests for the landinfluenced convective process on tropical cyclone formation are undergoing and will be presented in a future study.

Acknowledgments. This work was funded by the Korea Meteorological Administration Research and Development Program under the Center for Atmospheric Sciences and Earthquake Research (CATER) Grant 2012-2040. Professor R. L. Elsberry is supported by the Office of Naval Research Marine Meteorology section. Figures 10-12 were generated through a program on University of Utah PMM sciences site. Thus, the first author appreciates Dr. C. Liu at Texas A\&M for discussing the figures. Mrs. Penny Jones is acknowledged for her support in the manuscript preparation.

\section{REFERENCES}

Beattie, J. C., and R. L. Elsberry, 2012: Western North Pacific monsoon depression formation. Wea. Forecasting, 27, 14131432, doi:10.1175/WAF-D-11-00094.1.

Bell, M. M., and M. T. Montgomery, 2010: Sheared deep vortical convection in pre-depression Hagupit during TCS08. Geophys. Res. Lett., 37, L06802, doi:10.1029/2009GL042313.

Berry, G., and C. D. Thorncroft, 2005: Case study of an intense easterly wave. Mon. Wea. Rev., 133, 752-766, doi:10.1175/ MWR2884.1.

Bessafi, M., and M. C. Wheeler, 2006: Modulation of South Indian Ocean tropical cyclones by the Madden-Julian oscillation and convectively coupled equatorial waves. Mon. Wea. Rev., 134, 638-656, doi:10.1175/MWR3087.1.

Bister, M., and K. A. Emanuel, 1997: The genesis of Hurricane Guillermo: TEXMEX analyses and a modeling study. Mon. Wea. Rev., 125, 2662-2682, doi:10.1175/1520-0493(1997)125<2662: TGOHGT $>2.0 . \mathrm{CO} ; 2$.

Carr, L. E., and R. L. Elsberry, 1995: Monsoonal interactions leading to sudden tropical cyclone track changes. Mon. Wea. Rev., 123, 265-290, doi:10.1175/1520-0493(1995)123<0265: MILTST>2.0.CO;2.

Chen, S., W. Li, Y. Lu, and Z. Wen, 2014: Variations of latent heat flux during tropical cyclones over the South China Sea. Meteor. Appl., 21, 717-723, doi:10.1002/met.1398.

Eliassen, A., 1951: Slow thermally or frictionally controlled meridional circulation in a circular vortex. Astrophys. Norv., 5, 19-60.

Elsberry, R. L., and P. A. Harr, 2008: Tropical Cyclone Structure (TCS08) field experiment: Science basis, observational platforms, and strategy. Asia-Pac. J. Atmos. Sci., 44, 209-231.

Fovell, R. G., K. L. Corbosiero, and H.-C. Kuo, 2009: Cloud microphysics impact on hurricane track as revealed in idealized experiments. J. Atmos. Sci., 66, 1764-1778, doi:10.1175/2008JAS2874.1.

Griffiths, R. W., and E. J. Hopfinger, 1987: Coalescing of geostrophic vortices. J. Fluid Mech., 178, 73-97, doi:10.1017/ S0022112087001125.

Harr, P. A., and R. L. Elsberry, 1995: Large-scale circulation variability over the tropical western North Pacific. Part I: Spatial patterns and tropical cyclone characteristics. Mon.
Wea. Rev., 123, 1225-1246, doi:10.1175/1520-0493(1995)123<1225: LSCVOT>2.0.CO;2.

$\longrightarrow$, and - 1996: Structure of a mesoscale convective system embedded in Typhoon Robyn during TCM-93. Mon. Wea. Rev., 124, 634-652, doi:10.1175/1520-0493(1996)124<0634: SOAMCS $>2.0 . \mathrm{CO} ; 2$.

Hence, D. A., and R. A. Houze Jr., 2012: Vertical structure of tropical cyclones with concentric eyewalls as seen by the TRMM Precipitation Radar. J. Atmos. Sci., 69, 1021-1036, doi:10.1175/JAS-D-11-0119.1.

Hendricks, E. A., M. T. Montgomery, and C. A. Davis, 2004: The role of "vertical" hot towers in the formation of Tropical Cyclone Diana (1984). J. Atmos. Sci., 61, 1209-1232, doi:10.1175/1520-0469(2004)061<1209:TROVHT>2.0.CO;2.

Ho, C.-H., M.-S. Park, Y.-S. Choi, and Y. N. Takayabu, 2008: Relationship between intraseasonal oscillation and diurnal variation of summer rainfall over the South China Sea. Geophys. Res. Lett., 35, L03701, doi:10.1029/2007GL031962.

Hopsch, S. B., C. D. Thorncroft, and K. R. Tyle, 2010: Analysis of African easterly wave structures and their role in influencing tropical cyclogenesis. Mon. Wea. Rev., 138, 1399-1419, doi:10.1175/ 2009MWR2760.1.

Houze, R. A., Jr., W.-C. Lee, and M. M. Bell, 2009: Convective contribution to the genesis of Hurricane Ophelia (2005). Mon. Wea. Rev., 137, 2778-2800, doi:10.1175/2009MWR2727.1.

Hoyos, C. D., and P. J. Webster, 2007: The role of intraseasonal variability in the nature of Asian Monsoon precipitation. J. Climate, 20, 4402-4424, doi:10.1175/JCLI4252.1.

Huffman, G. J., and Coauthors, 2007: The TRMM Multisatellite Precipitation Analysis (TMPA): Quasi-global, multiyear, combined-sensor precipitation estimates at fine scales. $\mathrm{J}$. $\mathrm{Hy}$ drometeor., 8, 38-55, doi:10.1175/JHM560.1.

Iguchi, T., T. Kozu, R. Meneghini, J. Awaka, and K. Okamoto, 2000: Rain-profiling algorithm for the TRMM Precipitation Radar. J. Appl. Meteor., 39, 2038-2052, doi:10.1175/ 1520-0450(2001)040<2038:RPAFTT>2.0.CO;2.

Jiang, H., E. M. Ramirez, and D. J. Cecil, 2013: Convective and rainfall properties of tropical cyclone inner cores and rainbands from 11 years of TRMM data. Mon. Wea. Rev., 141, 431-450, doi:10.1175/MWR-D-11-00360.1.

Kim, H.-S., J.-H. Kim, C.-H. Ho, and P.-S. Chu, 2011: Pattern classification of typhoon tracks using the fuzzy $c$-means clustering method. J. Climate, 24, 488-508, doi:10.1175/2010JCLI3751.1.

Kim, J.-H., C.-H. Ho, H.-S. Kim, C.-H. Sui, and S. K. Park, 2008: Systematic variation of summertime tropical cyclone activity in the western North Pacific in relation to the Madden-Julian Oscillation. J. Climate, 21, 1171-1191, doi:10.1175/2007JCLI1493.1.

Lang, S. T. K., M. Leutbecher, and S. C. Jones, 2012: Impact of perturbation methods in the ECMWF ensemble prediction system on tropical cyclone forecasts. Quart. J. Roy. Meteor. Soc., 138, 2030-2046, doi:10.1002/qj.1942.

Li, T., and B. Fu, 2006: Tropical cyclogenesis associated with Rossby wave energy dispersion of a preexisting typhoon. Part I: Satellite data analyses. J. Atmos. Sci., 63, 1377-1389, doi:10.1175/JAS3692.1.

—, X. Ge, B. Wang, and Y. Zhu, 2006: Tropical cyclogenesis associated with Rossby wave energy dispersion of a preexisting typhoon. Part II: Numerical simulations. J. Atmos. Sci., 63, 1390-1409, doi:10.1175/JAS3693.1.

Liu, C., E. J. Zipser, D. J. Cecil, S. W. Nesbitt, and S. Sherwood, 2008: A cloud and precipitation feature database from nine years of TRMM observations. J. Appl. Meteor. Climatol., 47, 2712-2728, doi:10.1175/2008JAMC1890.1. 
Maloney, E. D., and D. L. Hartmann, 2001: The Madden-Julian Oscillation, barotropic dynamics, and North Pacific tropical cyclone formation. Part I: Observations. J. Atmos. Sci., 58, 2545-2558, doi:10.1175/1520-0469(2001)058<2545:TMJOBD>2.0.CO;2.

Mohr, K. I., and E. J. Zipser, 1996: Defining mesoscale convective systems by their $85 \mathrm{GHz}$ ice-scattering signature. Bull. Amer. Meteor. Soc., 77, 1179-1189, doi:10.1175/1520-0477(1996)077<1179: DMCSBT $>2.0 . \mathrm{CO} ; 2$.

Molinari, J., K. Lombardo, and D. Vollaro, 2007: Tropical cyclogenesis within an equatorial Rossby wave packet. J. Atmos. Sci., 64, 1301-1317, doi:10.1175/JAS3902.1.

Montgomery, M. T., M. E. Nicholls, T. A. Cram, and A. B. Saunders, 2006: A vortical hot tower route to tropical cyclogenesis. J. Atmos. Sci., 63, 355-386, doi:10.1175/JAS3604.1.

Nolan, D. S., 2007: What is the trigger for tropical cyclogenesis? Aust. Meteor. Mag., 56, 241-266.

Park, M.-S., and R. L. Elsberry, 2013: Latent heating and cooling rates in developing and nondeveloping tropical disturbances during TCS-08: TRMM PR versus ELDORA retrievals. J. Atmos. Sci., 70, 15-35, doi:10.1175/JAS-D-12-083.1.

— Y.-S. Choi, C.-H. Ho, C.-H. Sui, S. K. Park, and M.-H. Ahn, 2007: Regional cloud characteristics over the tropical northwestern Pacific as revealed by Tropical Rainfall Measuring Mission (TRMM) Precipitation Radar and TRMM Microwave Imager. J. Geophys. Res., 112, D05209, doi:10.1029/2006JD007437.

—, C.-H. Ho, J. Kim, and R. L. Elsberry, 2011: Diurnal circulations and their multi-scale interaction leading to rainfall over the South China Sea upstream of the Philippines during intraseasonal monsoon westerly wind bursts. Climate Dyn., 37, 1483-1499, doi:10.1007/s00382-010-0922-z.

_, R. L. Elsberry, and P. A. Harr, 2012: Vertical wind shear and ocean heat content as environmental modulations of western North Pacific tropical cyclone intensification and decay. Trop. Cyclone Res. Rev., 1 (4), 448-457.

, A. B. Penny, R. L. Elsberry, B. J. Billings, and J. D. Doyle, 2013: Latent heating and cooling rates in developing and nondeveloping tropical disturbances during TCS-08: Radar-equivalent retrievals from mesoscale numerical models and ELDORA. J. Atmos. Sci., 70, 37-55, doi:10.1175/JAS-D-11-0311.1.

Petersen, W. A., and S. Rutledge, 2001: Regional variability in tropical convection: Observations from TRMM. J. Climate, 14, 3566-3586, doi:10.1175/1520-0442(2001)014<3566:RVITCO >2.0.CO;2.

Ritchie, E. A., and G. J. Holland, 1999: Large-scale patterns associated with tropical cyclogenesis in the western Pacific. Mon. Wea. Rev., 127, 2027-2043, doi:10.1175/1520-0493(1999)127<2027: LSPAWT $>2.0 . \mathrm{CO} ; 2$.
Roundy, P. E., C. J. Schreck, and M. A. Janiga, 2009: Contributions of convectively coupled equatorial Rossby waves and Kelvin waves to the real-time multivariate MJO indices. Mon. Wea. Rev., 137, 469-478, doi:10.1175/2008MWR2595.1.

Sapiano, M. R. P., and P. A. Arkin, 2009: An intercomparison and validation of high-resolution satellite precipitation estimates with 3-hourly gauge data. J. Hydrometeor., 10, 149-166, doi:10.1175/ 2008JHM1052.1.

Spencer, R. W., H. M. Goodman, and R. E. Hood, 1989: Precipitation retrieval over land and ocean with the SSM/I: Identification and characteristics of the scattering signal. J. Atmos. Oceanic Technol., 6, 254-273, doi:10.1175/1520-0426(1989)006<0254: PROLAO $>2.0 . \mathrm{CO} ; 2$.

Straub, K. H., 2013: MJO initiation in the real-time multivariate MJO index. J. Climate, 26, 1130-1151, doi:10.1175/JCLI-D-12-00074.1.

Trenberth, K. E., 1986: An assessment of the impact of transient eddies on the zonal flow during a blocking episode using localized Eliassen-Palm flux diagnostics. J. Atmos. Sci., 43, 2070-2087, doi:10.1175/1520-0469(1986)043<2070:AAOTIO>2.0.CO;2.

Ventrice, M. J., C. D. Thorncroft, and M. A. Janiga, 2012: Atlantic tropical cyclogenesis: A three-way interaction between an African easterly wave, diurnally varying convection, and a convectively coupled atmospheric Kelvin wave. Mon. Wea. Rev., 140, 1108-1124, doi:10.1175/MWR-D-11-00122.1.

Waliser, D. E., and Coauthors, 2012: The "year" of tropical convection (May 2008-April 2010): Climate variability and weather highlights. Bull. Amer. Meteor. Soc., 93, 1189-1218, doi:10.1175/2011BAMS3095.1.

Wheeler, M. C., and H. H. Hendon, 2004: An all-season real-time multivariate MJO index: Development of an index for monitoring and prediction. Mon. Wea. Rev., 132, 1917-1932, doi:10.1175/1520-0493(2004)132<1917:AARMMI>2.0.CO;2.

Xu, Y., T. Li, and M. Peng, 2013: Tropical cyclogenesis in the western North Pacific as revealed by the 2008-09 YOTC data. Wea. Forecasting, 28, 1038-1056, doi:10.1175/ WAF-D-12-00104.1.

Yuter, S. E., and R. A. Houze Jr., 1995: Three-dimensional kinematic and microphysical evolution of Florida cumulonimbus. Part II: Frequency distributions of vertical velocity, reflectivity, and differential reflectivity. Mon. Wea. Rev., 123, 1941-1963, doi:10.1175/1520-0493(1995)123<1941: TDKAME $>2.0 . \mathrm{CO} ; 2$

Zhang, W., Y. Zhang, D. Zheng, and X. Zhou, 2012: Lightning distribution and eyewall outbreaks in tropical cyclones during landfall. Mon. Wea. Rev., 140, 3573-3586, doi:10.1175/ MWR-D-11-00347.1. 